\title{
Use of EpiAlveolar Lung Model to Predict Fibrotic Potential of Multiwalled Carbon Nanotubes
}

\author{
Hana Barosova, Anna G. Maione, Dedy Septiadi, Monita Sharma, Laetitia Haeni, Sandor Balog, \\ Olivia O’Connell, George R. Jackson, David Brown, Amy J. Clippinger, Patrick Hayden, Alke Petri-Fink, \\ Vicki Stone, and Barbara Rothen-Rutishauser*
}

Cite This: ACS Nano 2020, 14, 3941-3956

ABSTRACT: Expansion in production and commercial use of nanomaterials increases the potential human exposure during the lifecycle of these materials (production, use, and disposal). Inhalation is a primary route of exposure to nanomaterials; therefore it is critical to assess their potential respiratory hazard. Herein, we developed a three-dimensional alveolar model (EpiAlveolar) consisting of human primary alveolar epithelial cells, fibroblasts, and endothelial cells, with or without macrophages for predicting long-term responses to aerosols. Following thorough characterization of the model, proinflammatory and profibrotic responses based on the adverse outcome pathway concept for lung fibrosis were assessed upon repeated subchronic

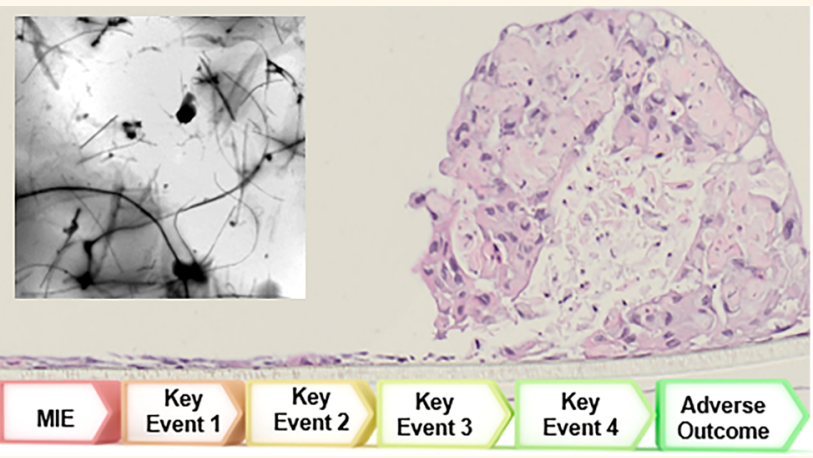
exposures (up to 21 days) to two types of multiwalled carbon nanotubes (MWCNTs) and silica quartz particles. We simulate occupational exposure doses for the MWCNTs $\left(1-30 \mu \mathrm{g} / \mathrm{cm}^{2}\right)$ using an air-liquid interface exposure device (VITROCELL Cloud) with repeated exposures over 3 weeks. Specific key events leading to lung fibrosis, such as barrier integrity and release of proinflammatory and profibrotic markers, show the responsiveness of the model. Nanocyl induced, in general, a less pronounced reaction than Mitsui-7, and the cultures with human monocyte-derived macrophages (MDMs) showed the proinflammatory response at later time points than those without MDMs. In conclusion, we present a robust alveolar model to predict inflammatory and fibrotic responses upon exposure to MWCNTs.

KEYWORDS: human primary cells, lung model, pulmonary fibrosis, multiwalled carbon nanotubes, air-liquid interface, long-term repeated exposures

$\mathrm{P}$ rogress in nanotechnology has led to increased production of various types of nanomaterials with unique properties. Thermal stability, electrical conductivity, and mechanical durability have made carbon nanotubes (CNTs) one of the most widely used nanomaterials, especially in the field of energy, electronics, and material composites. $^{1-5}$ The industrial use of CNTs could potentially cause adverse biological and environmental impact throughout their life cycle (i.e., from production to use and disposal). The biopersistence and high aspect ratio of CNTs is particularly of concern because exposure to these materials might induce pulmonary pathologies (e.g., pulmonary inflammation, fibrosis, mesothelioma, and other cancers) resembling those observed with micrometer-sized asbestos fibers. ${ }^{6-8}$ A growing number of animal tests demonstrate that exposure to multiwalled CNTs
(MWCNTs) potentially triggers airway injury, inflammation, fibrosis, and granuloma formation..$^{9-12}$ In particular, Mitsui-7 MWCNTs (henceforth referred to as Mitsui-7) have been shown to induce progressive fibrotic response in mice. ${ }^{12-14}$

Pulmonary fibrosis can be induced in response to a specific stimulus or as a consequence of the interactions of a substance with alveolar epithelium. ${ }^{15,16}$ Nanomaterials can reach the deepest regions of the lung (alveoli), depending on their

Received: August 29, 2019

Accepted: March 13, 2020

Published: March 13, 2020 
physicochemical properties, and induce a cascade of cellular responses $^{17}$ that lead to pulmonary fibrosis. ${ }^{15,18-20}$ This cascade of events can be organized into an adverse outcome pathway (AOP) framework. AOPs provide a means to organize existing knowledge about an adverse health effect starting with a molecular initiating event (MIE) that triggers subsequent key events (KEs) that occur at different levels of biological organization, which ultimately lead to an adverse outcome (AO). Organizing mechanistic information into an AOP helps identify causally connected KEs and informs the choice of the cell systems and assays best suited for investigating the biological outcome.

An AOP describing the mechanism of pulmonary fibrosis is being developed as a part of the Organisation for Economic Co-operation and Development (OECD) AOP Development Effort overseen by the Extended Advisory Group on Molecular Screening and Toxicogenomics. Several putative AOPs for pulmonary fibrosis with the potential MIE and KEs such as the one shown in Supplementary Figure 1 have been described previously. ${ }^{15,18,19,21}$ Of note here is that some of the KEs presented in Supplementary Figure 1 could overlap or occur simultaneously. Briefly, when a substance comes in contact with cellular membranes (MIE), a number of danger markers, called alarmins (an umbrella term for endogenous molecules that signal tissue and cell damage), are released as a part of an inflammatory response (KE1). The inflammatory response includes release of proinflammatory cytokines (e.g., tumor necrosis factor $\alpha$ (TNF- $\alpha$ ), interleukin (IL)- $1 \beta$, and IL-8) and an influx of leukocytes to the alveolar space, which precedes loss of alveolar barrier integrity (KE2). The purpose of the inflammatory response is to clear the foreign material from the tissue and to initiate repair, which is facilitated by growth factors, such as transforming growth factor $\beta$ (TGF- $\beta$ ). The repair process involves proliferation and migration of epithelial cells and differentiation of fibroblasts into myofibroblasts (KE3), which produce extracellular matrix (ECM) components (KE4) to repair the damage. Under physiological conditions, inflammation is resolved and normal alveoli structure and function is restored. However, in case of exposure to high doses or persistent stimulus, the repair process does not proceed properly. As a result, continued inflammation and excessive fibroblast and myofibroblast activation lead to increased ECM deposition and thickening of alveolar walls and, ultimately, to pulmonary fibrosis (AO). Choosing an assay or a battery of assays to measure the KEs along an AOP can help in designing testing strategies to predict complex outcomes such as pulmonary fibrosis.

While rodents have been used to characterize the whole lung response, these experiments are time-consuming, expensive, and of questionable human relevance and raise ethical concerns. As a result, in vitro lung systems are being increasingly used to investigate mechanisms of human toxicity following particle exposure. ${ }^{22,23}$ One example of widely used in vitro systems are three-dimensional (3D) reconstructed human respiratory tissue models that are grown at the air-liquid interface (ALI) and exhibit morphological and functional characteristics similar to the in vivo microenvironment. Reviews of in vitro models and recommendations on how to apply them to predict complex human outcomes have been described previously. ${ }^{22,24}$

In addition to choosing assays to measure specific KEs along an AOP, it is critical to consider test substance concentration and exposure methods that mimic human exposure conditions.
Many in vivo and in vitro studies were not designed to reflect a real-life occupational setting where exposures are likely to occur repeatedly over a long time frame. ${ }^{25}$ For example, several studies have been carried out using relatively high material doses, which may overwhelm normal defense mechanisms, thus resulting in significant initial pulmonary inflammation. $^{26-28}$ Additionally, many existing in vitro studies have been conducted under submerged conditions, which are less physiologically relevant than cells grown at the ALI since lung tissue is exposed to air on its apical surface. ALI exposure approaches provide a key strategy for mimicking inhalation toxicity. $^{29-33}$

The aim of this study was to design a test system of the lower respiratory tract that could be used to assess the fibrotic potential of substances. The use of an alveolar model in this study was important because the small size of MWCNTs allows them to penetrate deeply into the lung and probably deposit in the alveoli. We developed, characterized, and tested EpiAlveolar, a 3D reconstructed model of human alveolar tissue consisting of alveolar epithelial cells, fibroblasts, and endothelial cells, for its ability to recapitulate aspects of pulmonary fibrosis. In addition, human monocyte-derived macrophages (MDMs) were cocultured with the tissues to examine their potential role in the proinflammatory and profibrotic response. TGF- $\beta$ was used as a positive fibrotic control because of its involvement in the development of fibrosis in different organs, disturbances of the homeostatic microenvironment, promotion of cell activation, migration, and invasion, and excessive extracellular matrix production. ${ }^{34}$ Dörntruper quartz (DQ12) particles were selected as a positive control because they have been widely used in vitro to stimulate the proinflammatory response $\mathrm{s}^{35-37}$ and have been shown to stimulate the development of fibrosis in vivo. ${ }^{38-40}$ Two types of MWCNTs, Mitsui-7 and Nanocyl, were chosen as test materials because of the differences in their physicochemical properties. They have also been shown to induce the release of profibrotic mediators (TGF- $\beta$, platelet derived-growth factor, and osteopontin $)^{9,41-43}$ and up-regulate transcriptional and histological markers of fibrosis in vitro. Intratracheally instilled Nanocyl revealed a fibrotic response 28 days postexposure in mice. ${ }^{44}$ Mitsui-7 showed the potential to cause pulmonary fibrosis in mice in several studies, ${ }^{12,13,45,46}$ investigating gene regulation, ${ }^{46}$ lung burden, and thickness of connective tissue. ${ }^{12,13}$ In this study, the EpiAlveolar tissues were exposed to test aerosolized materials using a VITROCELL Cloud exposure system (VITROCELL Systems, Germany) allowing a dose-controlled deposition of the materials at the ALI. To mimic a realistic human exposure scenario, repeated, long-term exposures were conducted at low concentrations.

\section{RESULTS AND DISCUSSION}

Reliable testing approaches are needed to predict the risk, to support the safe-by-design concept, and for sustainable development of nanomaterials. Emerging tissue engineering technologies have resulted in effective and efficient humanrelevant methods that align with the 3 Rs principles. ${ }^{47}$ Human cell-based models (e.g., 3D lung tissue models) and ALI exposure devices have been developed during the past years, allowing for direct aerosolization of nanomaterials onto the surface of lung cells. ${ }^{33,48}$

The choice of test systems (i.e., cell types) and end points is specific to the research question and can be optimized by 


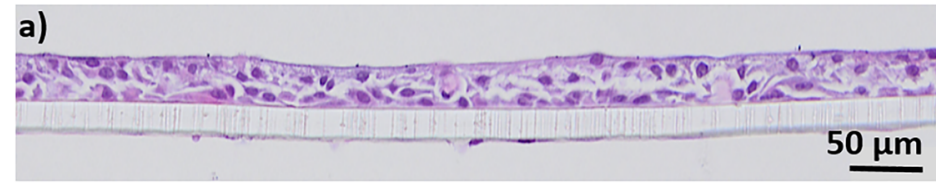

e)
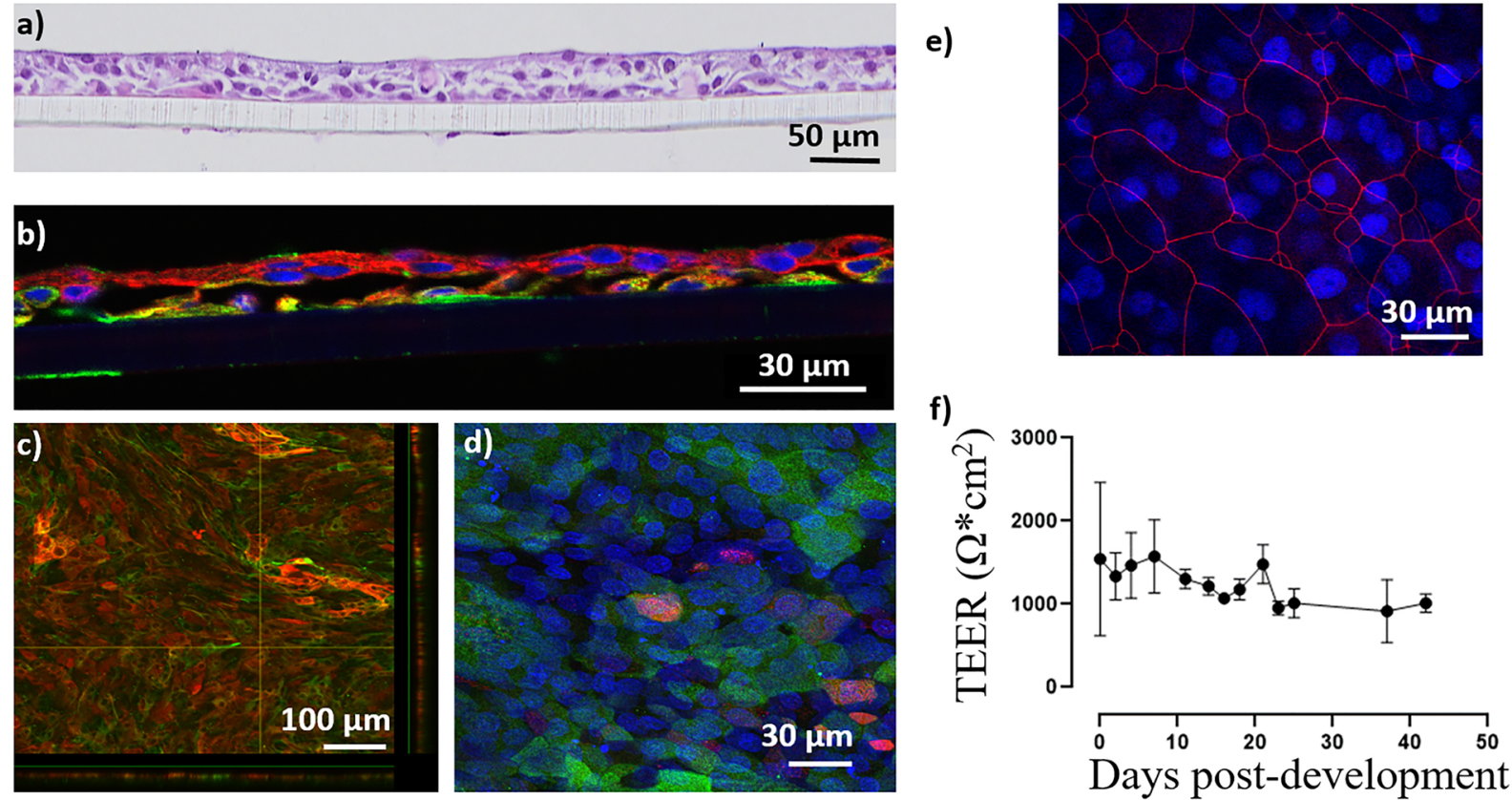

Figure 1. Characterization of EpiAlveolar model. (a) Hematoxylin and eosin staining showing the thickness of the tissues, that is, $2-4$ cell layers thick on the apical surface and a thin monolayer of endothelial cells on the basal surface. (b) Tissue sections showing the cell location within the tissue, that is, the layer of alveolar epithelial cells on top of the fibroblast (apical side) and endothelial cell (basal side) layers: epithelial marker cytokeratin 19 (CK19, red), mesenchymal cell marker vimentin (VIM, green), and DAPI (blue) staining cell nuclei. (c) Alveolar epithelial cell staining: ATI (CK19, red) and ATII cytokeratin 8 (CK8, green). (d) Whole mount staining of prosurfactant C (pSPC, red), a functional marker of ATII cells, and DAPI (blue) staining cell nuclei. (e) Immunofluorescsent staining for the epithelial tight junction marker ZO-1 (red) and cell nuclei (DAPI, blue). (f) Transepithelial electrical resistance values for up to 42 days after tissue development; data are presented as mean \pm standard deviation, $n=3$. Data obtained in Laboratory 1 .

considering the corresponding AOP. For example, the AOP for pulmonary fibrosis as depicted in Supplementary Figure 1 shows the development of fibrosis (the AO) preceded by key events (KEs), such as chronic inflammatory reactions, tissue remodeling, and repair processes, which are prerequisites for the development of the AO.

Submerged cell cultures using cell lines have revealed robust results with clear pathways such as direct exposure of fibroblasts to singlewalled CNTs increasing collagen type I and III production ${ }^{49}$ or exposure of epithelial cells (BEAS-2B) to singlewalled CNTs significantly increasing TGF- $\beta$ release. ${ }^{50}$ To predict further profibrotic events, the EpiAlveolar model was developed to mimic the in vivo human alveolar microenvironment, which includes cell types relevant to fibrosis, that is, human primary epithelial cells, endothelial cells, and fibroblasts. Our approach can build on data from submerged cell cultures by adding insights into further key events such as barrier properties and extracellular matrix tissues, two additional highly relevant KEs for the fibrotic adverse outcome.

Characterization of EpiAlveolar Model. EpiAlveolar is an in vitro organotypic model of the human alveolar tissue composed of primary human alveolar epithelial cells and pulmonary fibroblasts grown on the apical surface of a Transwell insert and primary pulmonary endothelial cells grown on the basal surface of the insert. The tissues were cultured at the ALI to induce differentiation and to simulate in vivo-like aerosol exposures.

The EpiAlveolar tissue model was evaluated for its ability to mimic characteristics of the alveolar microenvironment in vivo. The alveoli consist of an extremely thin epithelial layer surrounded by a network of capillaries to enable gas exchange.
To evaluate if the overall morphology of the EpiAlveolar tissues is similar, tissue cross sections were stained by hematoxylin and eosin (H\&E). Figure la shows that the EpiAlveolar tissues are approximately 2-4 cell layers thick on the apical surface with a thin monolayer of endothelial cells on the basal surface. Furthermore, tissue sections were stained by an epithelial marker, cytokeratin 19 (CK19), and a mesenchymal cell marker, vimentin (VIM), to show the layer of alveolar epithelial cells on top of the fibroblast (apical side) and endothelial cell (basal side) layers (Figure $1 \mathrm{~b}$ ). The in vivo alveolar epithelium consists of two cell types, type I (ATI) and type II (ATII). The presence of both cell types was verified in EpiAlveolar tissues by positive staining for cytokeratin 19 (CK19), an ATI marker, and cytokeratin 8 (CK8), an ATII marker (Figure 1c). Transmission electron microscopy micrographs confirmed the presence of lamellar bodies (Supplementary Figure 2a), membrane-bound structures containing stacked membranes of surfactant lipids. ${ }^{51}$ This result was further verified by whole mount staining of the tissues for expression of prosurfactant C (pSP-C), a critical feature of type II alveolar epithelial cells (Figure 1d). Additionally, surface tension of EpiAlveolar tissues, which is directly related to surfactant production, was evaluated at day 2 (Supplementary Figure $2 b, c)$ as previously described in the literature. ${ }^{52-54}$ The method relies on the fact that the diameter $(d)$ of a deposited droplet decreases with decreasing surface tension and vice versa. EpiAlveolar tissues were tested in three biological replicates $(n=3)$, while A549 cells served as assay control and were measured only once $(n=1)$. The graph (Supplementary Figure $2 b$ ) presents the relationship between drop ratio and surface tension. Surface tension of EpiAlveolar tissues is slightly higher than that measured in A549 cells, ${ }^{52}$ which could 
a)

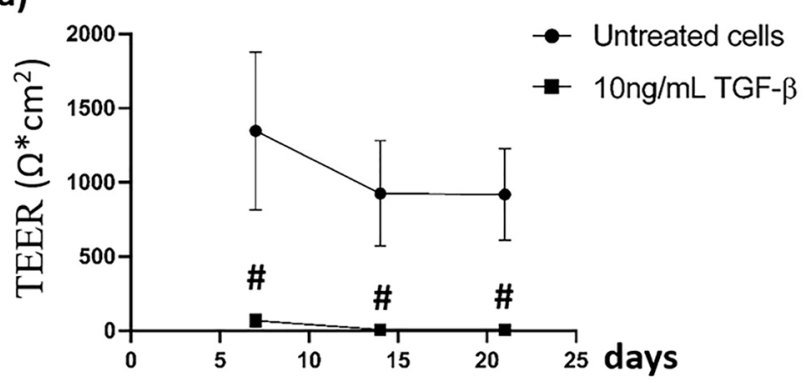

c)
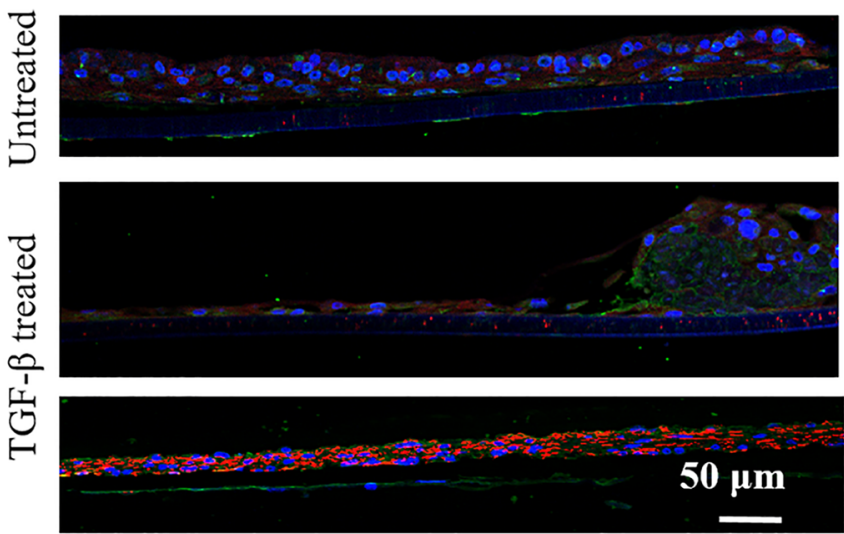

e)

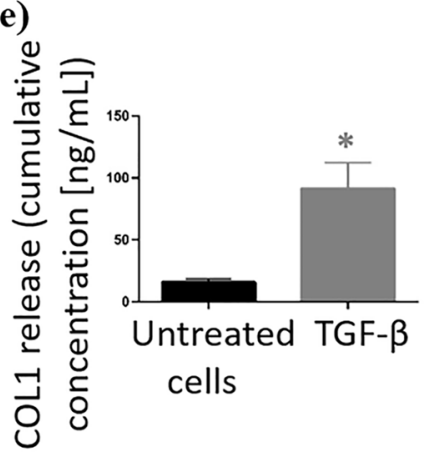

Figure 2. Characterization of EpiAlveolar model response. (a) Transepithelial electrical resistance value for untreated tissues and tissues upon exposure to TGF- $\beta$. Data are presented as mean \pm standard deviation, $n=3$. Data marked with \# were considered statistically significantly decreased $(p<0.05)$. (b) Hematoxylin and eosin staining showing the thickness of the untreated tissues, and nodule formation and tissue contraction upon exposure to TGF- $\beta$. (c) Fluorescent micrographs of untreated and TGF- $\beta$ treated tissues (scanned in two different areas) presenting $\alpha$-SMA (red) and fibronectin (green) expression, as well as nodule formation, upon exposure to TGF- $\beta$. Fibrotic response of tissues upon exposures to TGF- $\beta$ compared to untreated tissues: (d) fibronectin release; (e) COL1 release; data presented as cumulative dose during 21 days, mean \pm standard deviation, $n=3$. Data marked with * were considered statistically significantly increased $(p<0.05)$. Data obtained in Laboratory 1 .

be attributed to the fact that EpiAlveolar tissue consists of a mixture of alveolar epithelial type I and II cells. Although the measured surface tension is higher than seen in vivo, ${ }^{54}$ it is low enough to keep regular shape of a drop (Supplementary Figure $2 c)$, which confirms the presence of surfactants on the cellular surface. ${ }^{52,53}$ Further quantification of the ratio of the cell types, surface tension, and secretion of surfactant is ongoing. Having demonstrated the presence and spatial organization of the different alveolar cell types, we wanted to determine if the EpiAlveolar tissues form a barrier, which is an important function of the in vivo tissue and is not well developed when using alveolar cell lines, such as A549 cells. ${ }^{55}$ Barrier function was assessed by visualization of tight junctions (Figure 1e) and measuring the transepithelial electrical resistance (TEER) over time. A TEER value $\geq 300 \Omega \cdot \mathrm{cm}^{2}$ was considered indicative of an intact barrier based on previous manufacturer experiments and recommendations. The mean TEER value of EpiAlveolar tissues was highest the first week after completing differentiation, decreased slightly, and then stabilized around 1000 $\Omega \cdot \mathrm{cm}^{2}$ (Figure 1f). TEER remained high for approximately one month in culture, indicating that the tissue barrier remained intact. This is important because it allows barrier integrity to be assessed throughout long-term, repeated exposure experiments. Following characterization of the EpiAlveolar model, the tissues were challenged with different treatments and end points were assessed related to the pulmonary fibrosis pathway in humans as depicted in the AOP schematic (Supplementary Figure 1).

Cellular Interaction of the Substance (MIE). Pulmonary fibrosis is initiated by a variety of stimuli including persistent infections, autoimmune reactions, allergic responses, chemical insults, radiation, and tissue injury. MWCNTs have also previously been shown to reach the lower respiratory tract and cause lung fibrosis in vivo. ${ }^{12,42}$

It is worth mentioning that deposited materials on the cellular surface can trigger a cascade of inflammatory mediator and growth factor release, which activates fibroblast proliferation and extracellular matrix production, and therefore, uptake by cells or translocation to cells located beneath the alveolar epithelial layer is not the only condition for development of pulmonary fibrosis. In addition, the barrier impairment could increase the translocation of the materials across the alveolar tissue, but with the herein used inserts having small pore sizes $(0.4 \mu \mathrm{m})$, this might be less probable.

Positive Controls Induced Proinflammatory and Profibrotic Responses in the EpiAlveolar Model. Before testing the effects of aerosol exposure to nanomaterials, it was first necessary to demonstrate that a profibrotic phenotype could be induced in the EpiAlveolar tissues. Toward this goal, barrier function, tissue morphology, and profibrotic markers 


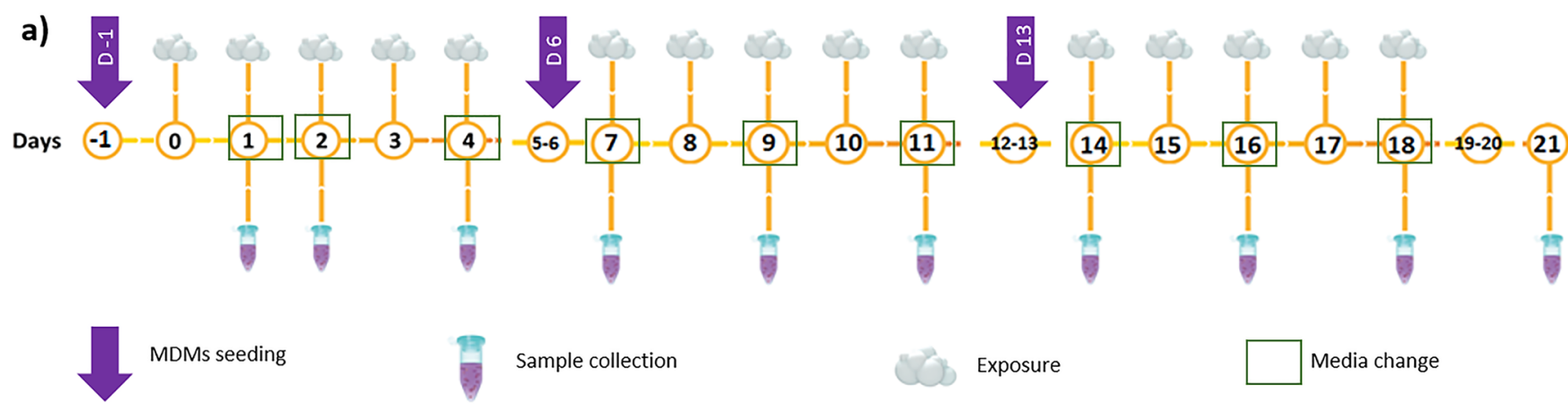

b)

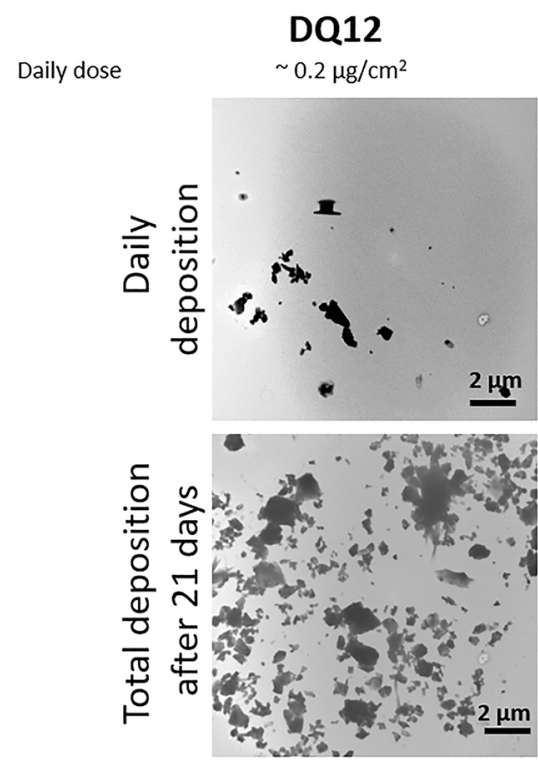

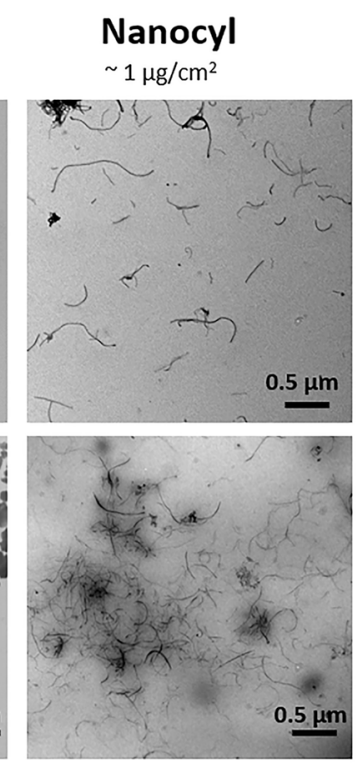

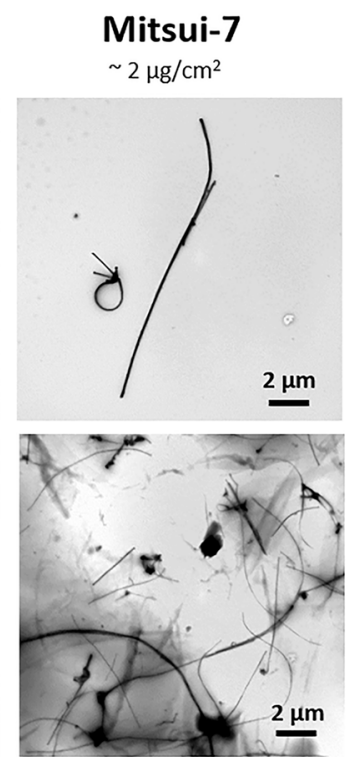

Figure 3. Exposure scenario and characterization of investigated particles inside the VITROCELL Cloud exposure chamber. (a) MDM seeding and exposure scenario. MDMs were seeded every Sunday (days (D) 1, 6, and 13) prior to starting each week of exposures. EpiAlveolar tissues (with (+) and without $(-)$ MDMs) were exposed every working day from Monday to Friday ( 5 times per week) for 3 consecutive weeks. For each experiment, the exposure chamber was wiped and the medium in the exposure chamber was changed between exposures. (b) TEM micrographs of deposited particles (DQ12, Nanocyl, and Mitsui-7) on TEM grids placed at the bottom of the VITROCELL Cloud exposure chamber. Upper line corresponds to deposited amount of particles in 1 day; lower line corresponds to overall deposition during whole experiment, that is, after 3 weeks (15 days of exposures). Data obtained in Laboratory 2.

were assessed following treatment with TGF- $\beta$, a known chemical inducer of fibrosis. ${ }^{34,56-59}$ To ensure the reproducibility of the result, characterization experiments were conducted independently in three laboratories (MatTek Corp. (Laboratory 1), Adolphe Merkle Institute (Laboratory 2 ), and Heriot-Watt University (Laboratory 3)).

After approximately 12 days of $10 \mathrm{ng} / \mathrm{mL}$ TGF- $\beta$ treatment, EpiAlveolar tissues began to contract away from the Transwell insert and round up. This contraction resulted in reduced TEER and, subsequently, complete loss (statistically significant decrease, $\sim 10 \Omega \cdot \mathrm{cm}^{2}$ ) of TEER at day 21 (Figure $2 \mathrm{a}$, data from Laboratory 1). Conversely, the untreated tissues maintained barrier function for 21 days, with no significant difference between the two untreated conditions $\left(\sim 1000 \Omega \cdot \mathrm{cm}^{2}\right)$. Similar to Laboratory 1 , there was an evident drop in TEER upon exposure to TGF- $\beta$ compared to untreated cells at day 21 in Laboratory 2 and at days 12 and 21 in Laboratory 3 (Supplementary Figure 3).

Homeostasis in the lung tissue depends on tightness of the alveolar lining layer to provide a tight barrier against inhaled foreign substances (e.g., microorganisms and particulate matter). ${ }^{60}$ Treatment of EpiAlveolar with TGF- $\beta$ abolished the TEER after day 7. In comparison, untreated tissues sustained a TEER of $1000 \Omega \cdot \mathrm{cm}^{2}$, indicating an intact barrier for the entire duration of the experiment ( 21 days). It was previously shown that primary human ATI cells can develop resistance between 1000 and $2000 \Omega \cdot \mathrm{cm}^{2}$ when cultured in vitro, ${ }^{51}$ which correlates with our results over the entire 3 week period in culture at the ALI and was confirmed in three independent laboratories. Treatment with MWCNTs and DQ12 showed a slight decrease in TEER after 21 days, but clear conclusions could not be drawn because of variability between the readings.

EpiAlveolar tissues began showing a slightly denser ECM around 7 days of treatment as shown in the H\&E-stained cross sections. By 12 days of treatment, large nodules of tissue were visible, likely due to tissue contraction and increased ECM deposition (data not shown, data from Laboratory 1). These nodules were more prevalent at day 21 of TGF- $\beta$ treatment, and the centers of the nodules began to look somewhat necrotic, perhaps due to their large size (Figure $3 b$ ). Furthermore, TGF- $\beta$-treated tissues exhibited increased expression of $\alpha$ smooth muscle actin ( $\alpha$-SMA, Figure 2c), a major constituent of the contractile apparatus found in 
myofibroblasts during wound healing and fibrosis, compared to untreated cells. The contracted tissue morphology following TGF- $\beta$ was not evident in Laboratory 2 via laser scanning microscopy (LSM), which could be due to the technical difficulty of preserving the nodules during tissue preparation. Laboratory 3 confirmed the results of Laboratory 1, seeing contraction and nodule formation following 21 days of TGF- $\beta$ exposure (Supplementary Figure 3). It should be noted that once the tissues started to contract, they were extremely prone to detachment from the insert membrane.

TGF- $\beta$ treatment of EpiAlveolar tissues induced another hallmark of fibrosis: increased expression of ECM proteins, such as fibronectin and collagen. Immunofluorescence staining for fibronectin was increased in the EpiAlveolar tissues treated with TGF- $\beta$ for 21 days compared to untreated tissues (Figure $2 c)$. Similarly, the concentration of fibronectin released into the tissue culture media was significantly higher in the tissues exposed to TGF- $\beta$ compared to untreated tissues over all experiments (Figure 2d). Secretion of type I, $\alpha$-1 collagen (COL1) was also significantly increased $(p<0.01)$ in the media of TGF- $\beta$-treated tissues as cumulative dose over 21 days (Figure 2e). Taken together, these results show that the positive control, TGF- $\beta$, was able to induce a profibrotic response in EpiAlveolar tissues.

Characterization of MWCNT and DQ12 Exposures in Laboratory 2. Following experiments confirming that the EpiAlveolar tissues can be cultured long-term and are responsive to inflammatory and fibrotic stimuli, the tissues were evaluated in Laboratory 2 after subchronic exposure to two MWCNTs, Mitsui-7 and Nanocyl, and the positive control, silica quartz particles (DQ12).

The EpiAlveolar tissues were exposed to aerosolized MWCNTs and DQ12 every working day from Monday to Friday (five times per week) for three consecutive weeks to mimic repeated occupational exposure. The scheme in Figure 3 a depicts the days of exposures, sample collection, and media changes. The basolateral media samples collected on days 1,4 , $7,11,14,18$, and 21 from three experiments were chosen for analysis based on preliminary data from the first experiment.

In addition to choosing cell systems relevant to the target biological site, it is critical to choose test concentrations that are representative of realistic human exposures. In this study, particle exposure was performed with the VITROCELL Cloud system, which allows a dose-controlled and spatially uniform deposition of aerosolized drugs ${ }^{61}$ or nanomaterials. ${ }^{62,63}$ EpiAlveolar tissues were exposed to repeated subchronic exposures of MWCNTs and DQ12 particles at realistic concentrations.

Prior to the cell exposures, the particles were carefully characterized. To visualize dispersed particles, prior to further exposures (nebulization), the liquid stock solutions of MWCNTs and DQ12 were pipetted onto transmission electron microscopy (TEM) grids and visualized using TEM (Supplementary Figure 4). To investigate the material deposited within the exposure chamber (VITROCELL Cloud), a TEM grid was placed in the bottom of the exposure chamber, and the deposited material was imaged by TEM following one aerosol exposure (day 1 dose) and 15 exposures (day 21 dose) (Figure $3 \mathrm{~b}$ ). The representative TEM images of aerosolized particles (Mitsui-7, Nanocyl, and DQ12) present a homogeneous and dose-dependent deposition comparing day 1 and day 21. Furthermore, Mitsui-7 appears as singlets or small bundles of thicker tubes, while Nanocyl are shorter and thinner tangled tubes. DQ12 showed single particle deposition at day 1 and some aggregated particles at day 21, resulting from repeated particle deposition. The aerosolized particles were well distributed on the TEM grid surface because of single droplet deposition, and it was observed that aerosolization did not affect particle size or shape. These results demonstrate that the VITROCELL Cloud system is suitable for aerosol exposure of such materials and that the dispersed materials demonstrate similar characteristics as the suspension materials.

In addition to the qualitative assessment of deposited material using TEM, the daily deposition was quantified using a quartz crystal microbalance (QCM). It was not technically possible to measure the repeated exposure doses (every working day during 3 weeks) via QCM, because only one device is available in our laboratory and several exposures of different materials were performed daily. Therefore, each daily exposure was measured, and the average deposition was multiplied by number of exposures to estimate the weekly $(\times 5)$ or total $(\times 15)$ deposition (Supplementary Figure 5). Daily depositions of Mitsui-7 (2 different doses were investigated) were therefore estimated to be $\sim 0.9 \mu \mathrm{g} / \mathrm{cm}^{2}$ and $\sim 2 \mu \mathrm{g} / \mathrm{cm}^{2}$, while total depositions increased to $\sim 13.5 \mu \mathrm{g} /$ $\mathrm{cm}^{2}$ and $\sim 29.6 \mu \mathrm{g} / \mathrm{cm}^{2}$. Nanocyl daily deposition was $\sim 1 \mu \mathrm{g} /$ $\mathrm{cm}^{2}$ and total deposition reached $\sim 15.2 \mu \mathrm{g} / \mathrm{cm}^{2}$, and DQ12 daily deposition was $\sim 0.2 \mu \mathrm{g} / \mathrm{cm}^{2}$ while total deposition increased to $\sim 2.7 \mu \mathrm{g} / \mathrm{cm}^{2}$. The depositions were reproducible among different wells within the chamber $(\sim 4.3 \%$ as previously shown ${ }^{61}$ ) as well as in a day-to-day manner.

The alveolar mass retention of a full working lifetime exposure (45 years) to CNTs of different sizes was modeled and calculated to be in the range of 12.4 to $46.5 \mu \mathrm{g} / \mathrm{cm}^{2}{ }^{64}$ Herein, the maximal deposited concentration for Nanocyl was $15 \mu \mathrm{g} / \mathrm{cm}^{2}$, and those for Mitsui-7, two concentrations were tested, resulting in $15 \mu \mathrm{g} / \mathrm{cm}^{2}$ and $30 \mu \mathrm{g} / \mathrm{cm}^{2}$, respectively, within the 3 weeks of repeated exposures. The applied doses are in the range of the reported lifetime human exposure to MWCNTs; ${ }^{64}$ however, we still have to keep in mind that we only assess the effects within 3 weeks. On the other hand, the lowest applied concentration $\left(1 \mu \mathrm{g} / \mathrm{cm}^{2}\right)$ for Mitsui-7 and Nanocyl corresponds with concentrations used in mice in vivo. ${ }^{14,46}$ Moreover, the positive particle control DQ12 (crystalline quartz) has previously been used in vitro to stimulate the proinflammatory response $\mathrm{s}^{35-37}$ and in vivo to stimulate the development of fibrosis. ${ }^{38,65}$ In our studies, aerosolization of DQ12 resulted in an average deposited concentration of $\sim 0.2 \mu \mathrm{g} / \mathrm{cm}^{2}$, and after repeated exposures, the concentration was $\sim 2.7 \mu \mathrm{g} / \mathrm{cm}^{2}$. Applied concentrations correspond to those used in previous in vitro studies that resulted in a proinflammatory response. ${ }^{35,66}$ Furthermore, these concentrations are comparable to in vivo experiments in rats $\left(3-30 \mathrm{mg} / \mathrm{rat}^{38}{ }^{38}\right.$ which corresponds to $0.6-6 \mu \mathrm{g} / \mathrm{cm}^{2}$, deposition calculated based on ref 67).

Coculture of EpiAlveolar with Macrophages (Laboratory 2). It has been demonstrated that macrophages obtained from patients with lung fibrosis overproduce proinflammatory cytokines and growth factors such as TNF$\alpha$, IL- 1 , and TGF- $\beta .^{68}$ Therefore, to understand the role of macrophages in fibrosis development, we cocultured EpiAlveolar tissues with MDMs. Fresh MDMs were seeded each week (schematic marking days of seeding in Figure 3a) on the apical surface of the EpiAlveolar tissues $((+) \mathrm{MDMs})$, and the response was compared to tissues without MDMs ((-) 
a)

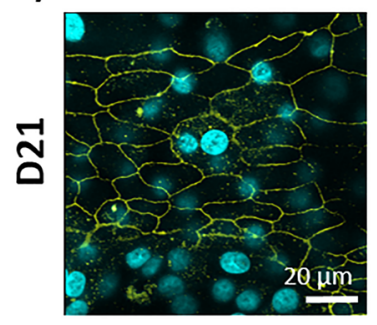

Untreated cells

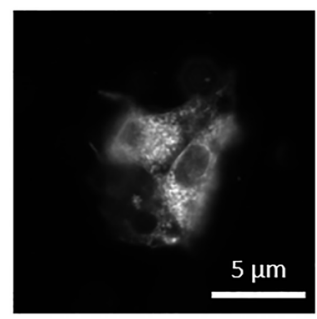

b)

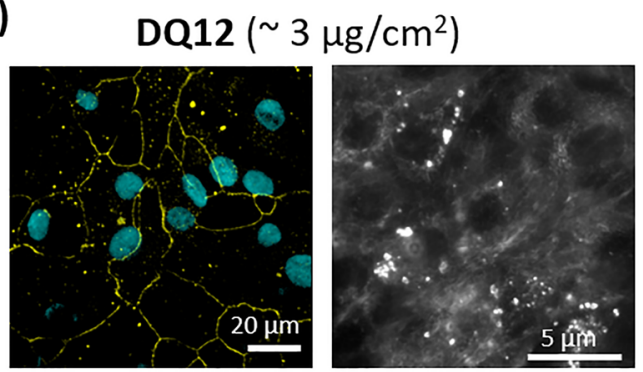

d)

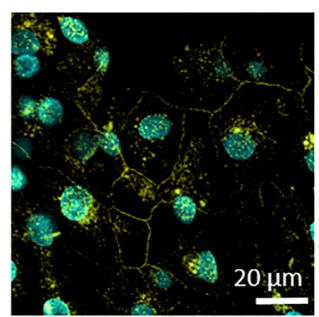

Mitsui-7 ( $\left.30 \mu \mathrm{g} / \mathrm{cm}^{2}\right)$

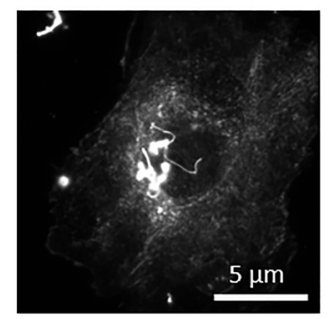

Nanocyl ( $\left.15 \mu \mathrm{g} / \mathrm{cm}^{2}\right)$

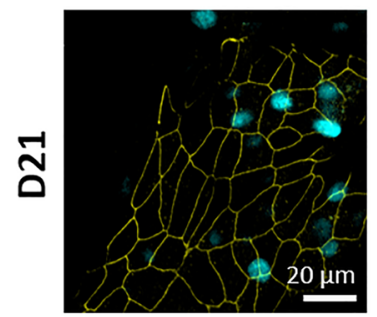

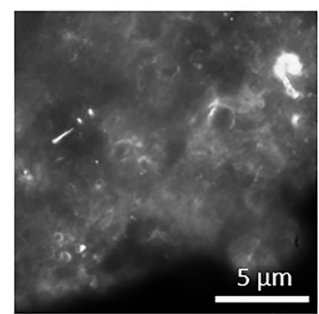

Figure 4. Representative laser scanning microscopy images presenting tight junctions of tissue and enhanced dark-field microscopy images showing interaction of investigated materials with cells. Tight junctions (left) and enhanced dark-field image (right) of tissue at day 21 : (a) untreated cells, (b) DQ12-treated, (c) Nanocyl-treated, and (d) Mitsui-7 (higher dose)-treated. Cyan represents nucleus; yellow represents tight junctions (ZO-1). Data obtained in Laboratory 2.

MDMs). MDM localization within the tissue was visualized via anti-macrophage mannose receptor (also known as CD206) staining using LSM. It was observed that MDMs are still present in tissues after 21 days of exposures (Supplementary Figure 6). Exposures to DQ12 and Mitsui-7 do not affect the presence of MDMs (Supplementary Figure 5b,c) compared to bovine serum albumin (BSA)-treated samples (Supplementary Figure 5a), and they are located on the apical side of the EpiAlveolar tissues (Supplementary Figure 6d).

Particle Interaction with EpiAlveolar and Their Effect on Barrier Tightness (Laboratory 2). Fluorescenceenhanced dark-field imaging was used to visualize the distribution of Mitsui-7 in the EpiAlveolar tissues with $(+)$ and without (-) MDMs at D21. Representative 3D rendered images (Supplementary Figure 7a,c) and $x y$ projections (Supplementary Figure 7b,d) show that the Mitsui-7 (white arrows pointing to Mitsui-7) are associated with cells within the EpiAlveolar tissues $(+)$ and $(-)$ MDMs. No difference in Mitsui-7 locations was observed when comparing tissues (+) and (-) MDMs. Since the tissues were grown on poly(ethylene terephthalate) (PET) membrane inserts, a strong scattering of the insert pores resulted in artifacts (roundshaped green objects), and Nanocyl and DQ12 particles did not provide enough contrast to be visualized. Therefore, further experiment was performed. Fixed tissues were scraped using a cell scraper, resuspended in Kaiser's glycerol, and dropped on a glass slide. As-prepared samples were visualized using fluorescence-enhanced dark-field imaging. We could clearly confirm the presence of all tested materials with cells extracted from the tissue (Figure 4). The cell type, however, could not be determined by this method.

As barrier integrity is an important feature of epithelial cells, tight junctions of EpiAlveolar tissues (-) MDMs were visualized via zonula occludens 1 , a tight junction protein, ${ }^{69}$ after 21 days of exposures (Figure 4). Exposures to DQ12 and Nanocyl did not affect tight junction formation. Exposures to Mitsui-7 affected formation of tight junctions; they appear weaker. It is worth mentioning, that the surface of EpiAlveolar is not flat and therefore we can observe patches with and without tight junctions.

No Cytotoxicity Was Observed upon Material Exposure (Laboratory 2). Cytotoxicity (lactate dehydrogenase $(\mathrm{LDH})$ release) was investigated in response to particle (Mitsui-7, Nanocyl, and DQ12) exposures. No statistically significant $(p>0.05)$ increase in $\mathrm{LDH}$ release into the basolateral media was observed for all tested materials at days 7,14 , and 21 in both (+) and (-) MDMs tissues (Supplementary Figure 8).

Cellular Morphology Was Significantly Altered upon Exposure to TGF- $\boldsymbol{\beta}$ (Laboratory 2). EpiAlveolar tissues (-) MDMs were treated with Mitsui-7 (daily deposition $\sim 2 \mu \mathrm{g}$ / $\mathrm{cm}^{2}$ ) and imaged using LSM to observe cell morphology. No overt changes in epithelial cell or fibroblast morphology were evident when compared to negative control (BSA treatment) (Supplementary Figure 9). However, gaps or holes in the endothelial cell layer were observed in the Mitsui-7-exposed tissues. Exposures to DQ12 and Nanocyl showed a similar pattern, but loss in endothelial cell continuity was less obvious (data not shown). The TGF- $\beta$ treatment $[50 \mathrm{ng} / \mathrm{mL}]$ led to changes in all cell types; they lost their regular shape, became disorganized, and lost cell-cell contact, which caused discontinuity of the cellular layer on both sides of the insert.

Release of Proinflammatory Mediators Was Significantly Increased upon Exposures to Positive Controls, DQ12, Nanocyl, or Mitsui-7 in Laboratory 2 (KE 1). TNF$\alpha$, IL-1 family cytokines, IL-6, and IL- 8 are proinflammatory mediators that play important roles in local injury and inflammatory reaction in development of human pulmonary fibrosis. $^{70,71}$ The release of these cytokines was assessed by Enzyme Linked Immunosorbent Assay (ELISA) following treatment of EpiAlveolar tissues with the positive controls (TNF- $\alpha$, lipopolysaccharide (LPS), or TGF- $\beta$ ) or with particles (Figure 5 and Supplementary Figures 10 and 11). 
a)

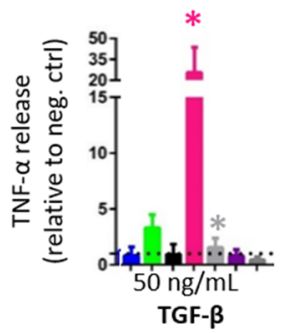

c)

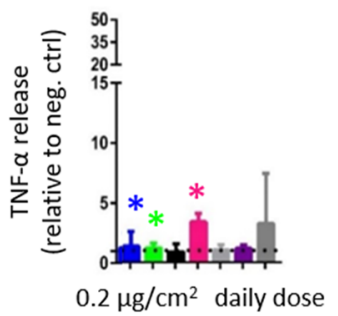
DQ12

g)

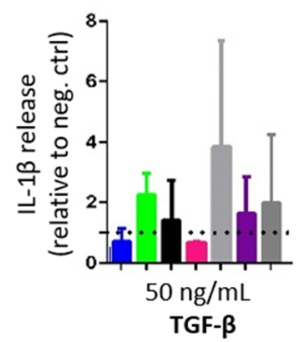

i)

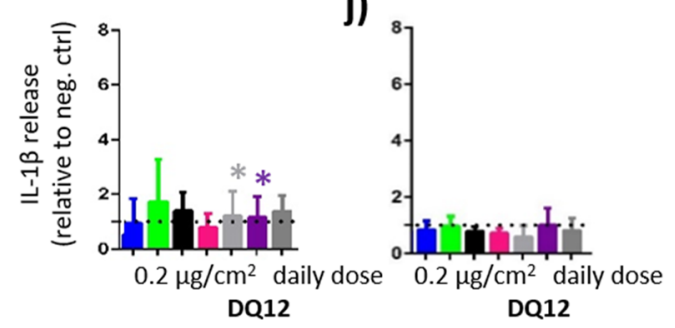

(+) MDMs

b)

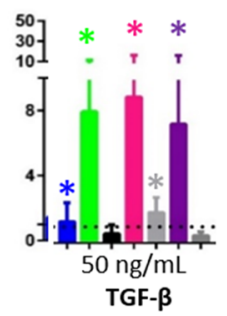

d) 5

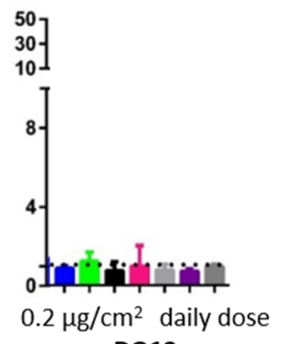

DQ12 h) $\left.{ }^{8}\right] * \quad$ k) e)

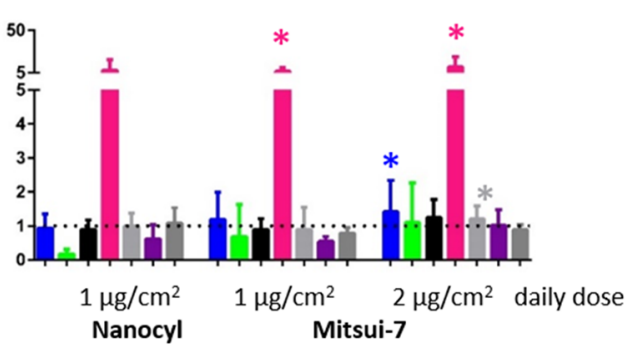

f)

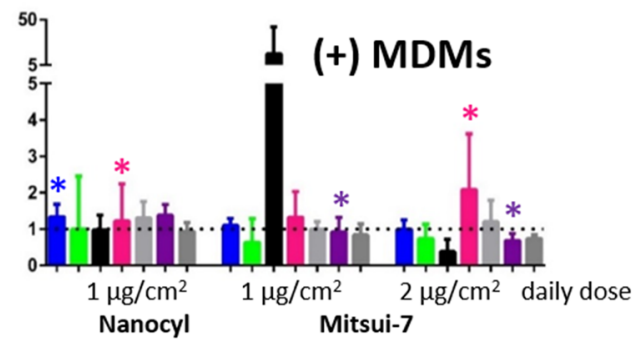

(-) MDMs

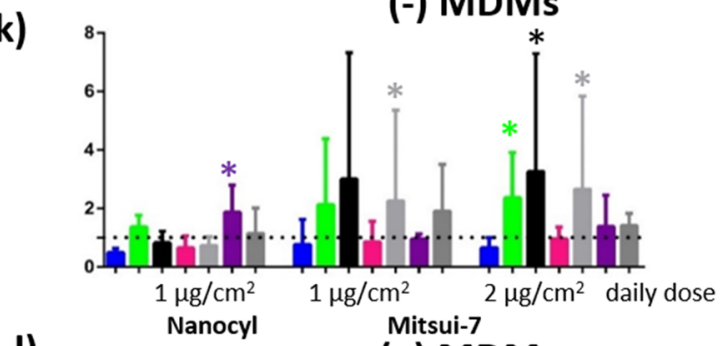

I)

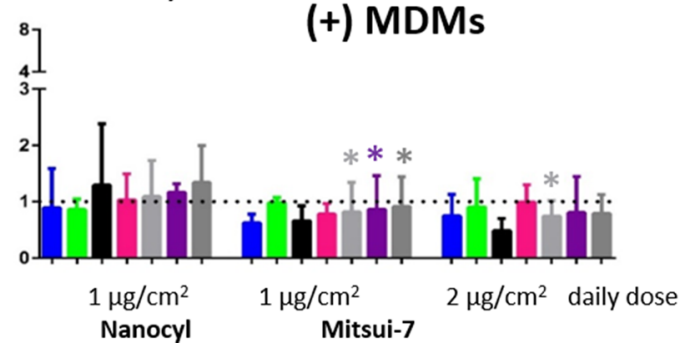

Figure 5. Tumor necrosis factor $\alpha(a-f)$ and interleukin $1 \beta(g-1)$ release as a marker of proinflammatory response from tissues without macrophages and with macrophages. Data are presented as relative to negative control (dashed line); untreated cells served as negative control for positive control-treated cells $(a, b, g, h)$, and DQ12 treated tissues $(c, d, i, j)$, while BSA-treated cells served as negative control for MWCNT-treated cells $(e, f, k, 1)$. Data are presented as mean \pm standard deviation, $(n=3)$. Data marked as with * were considered statistically significantly $(p<0.05)$ increased compared to negative control. Data obtained in Laboratory 2.

Tissues exposed to inflammatory positive controls (LPS and TNF- $\alpha$ ) showed general response following the proinflammatory cascade; ${ }^{71}$ that is, TNF- $\alpha$ resulted in earlier response in IL-8 release, while tissues treated with LPS showed an increase in IL- 8 production at later time points. No increase in TNF- $\alpha$ and IL-6 release was observed at D21, interestingly IL-6 release was significantly increased upon exposures to all positive controls (LPS, TNF- $\alpha$, and TGF- $\beta$ ) at most of the time points (Days 1-18). On the other hand, tissues showed a statistically significant increase in all investigated cytokines released after exposure to Mitsui-7. In general, lower concentrations ( $\sim 1 \mu \mathrm{g})$ $\mathrm{cm}^{2}$ ) induced a proinflammatory response at a later time point (Day 11), while the higher concentration $\left(\sim 2 \mu \mathrm{g} / \mathrm{cm}^{2}\right)$ induced a proinflammatory response as early as Day 1 . Nanocyl induced, in general, a less pronounced reaction than Mitsui-7, a finding consistent with previously published results investigating the response of $2 \mathrm{D}$ monocultures of epithelial cells, fibroblasts, or macrophages in vitro. ${ }^{41}$ Similar results were published also from in vivo study, where intratracheally instilled Nanocyl showed a fibrotic response 28 days postexposure in mice, which was less pronounced compared to longer MWCNTs with higher diameter. ${ }^{44}$ The EpiAlveolar tissues with added MDMs presented the proinflammatory response at later time points (days 14 and 18), which could indicate that MDMs initially reduced exposure to particles by clearance from the ALI surface of the epithelial cells, but over time, they released either the material or proinflammatory mediators, which stimulate the epithelial cells, so that the response is delayed. This indicates that MDMs are able to counterbalance the immune reaction to a certain extent until the response becomes uncontrolled. It has been reported from in vivo studies in mice that an acute inflammatory phase response started 1 day after exposure to $40 \mu \mathrm{g}$ of Mitsui-7, peaked 7 days after aspiration, and was always increased compared to negative control for all investigated time points, up to 56 days. ${ }^{14}$ Although in this study the tissues showed a statistically 
a)

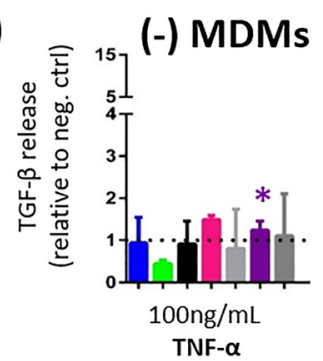

c)

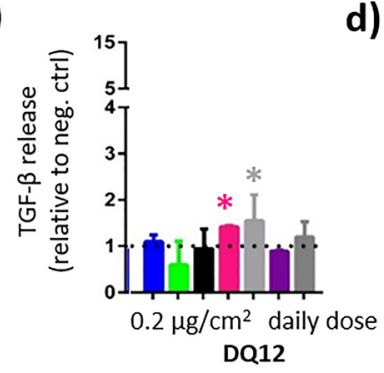

b)

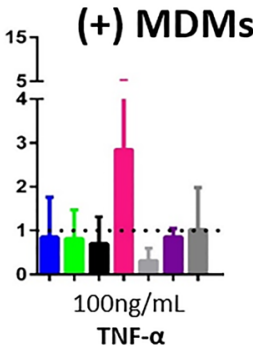

d)

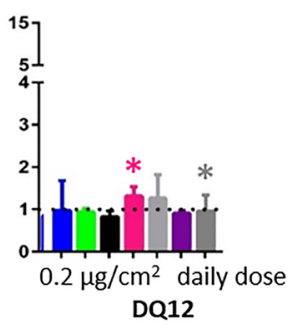

e)

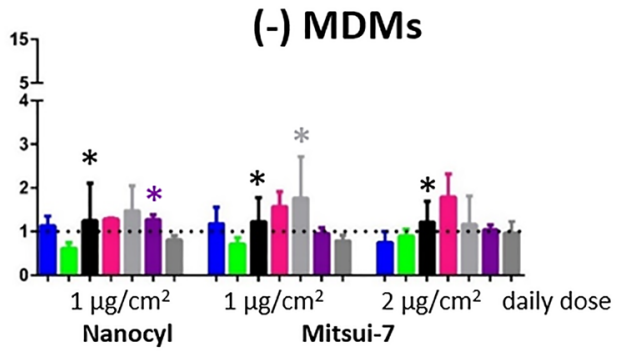

f)

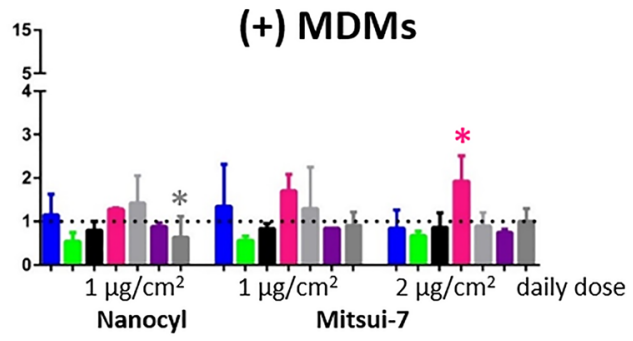

D1

D4

$\square$ D7

D11

D14

D18

D21

g)

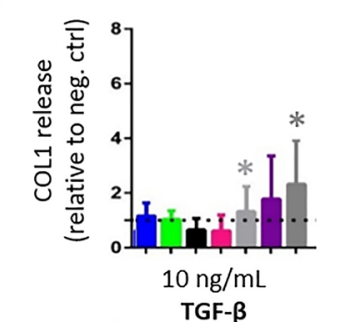

i)

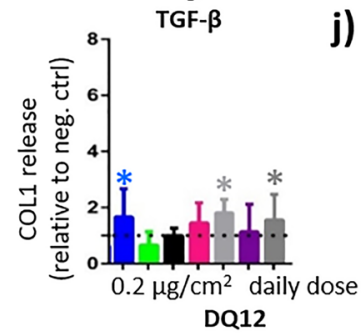

h)

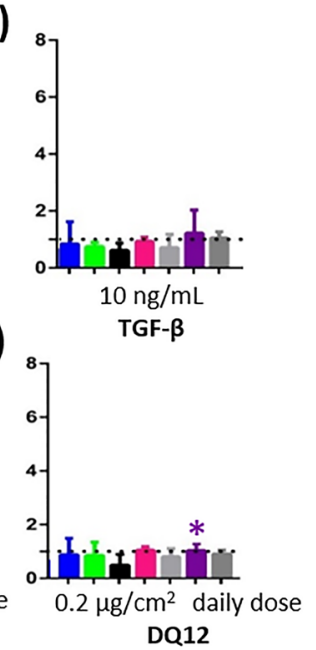

k)

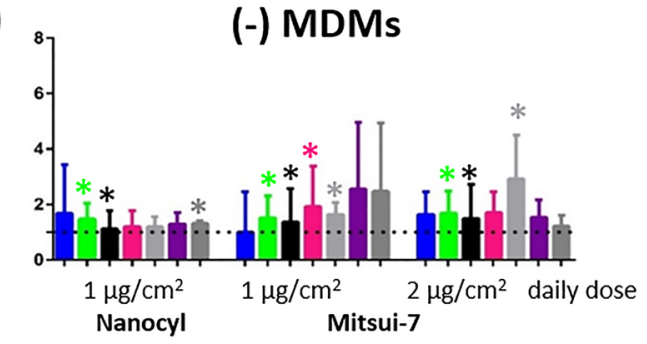

I)

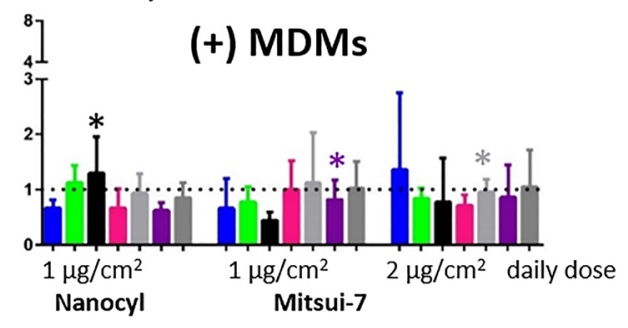

Figure 6. Transforming growth factor $\beta(\mathrm{a}-\mathrm{f})$ and collagen type $1 \alpha 1(\mathrm{~g}-\mathrm{l})$ release as a marker of profibrotic response from tissues without macrophages and with macrophages. Data are presented as relative to negative control (dashed line); untreated cells served as negative control for positive control-treated cells $(a, b, g, h)$ and DQ12 treated tissues $(c, d, i, j)$, while BSA-treated cells served as negative control for MWCNT-treated cells $(e, f, k, 1)$. Data are presented as mean \pm standard deviation, $(n=3)$. Data marked with * were considered statistically significantly $(p<0.05)$ increased compared to negative control. Data obtained in Laboratory 2.

significant increase in cytokine release after exposure to both Mitsui-7 and Nanocyl, the response did not show a clear dose or time dependence. Future studies could normalize ELISA results to cell numbers to decrease the variability observed in cytokine release.

In EpiAlveolar tissues (-) MDMs, the positive particle control DQ12 induced significant TNF- $\alpha$, IL- $1 \beta$, and TGF- $\beta$ release. This response is comparable to a previous study, where in vitro bronchial cells (without MDMs) from healthy (nonasthmatic) donors developed a significant proinflammatory (IL-8) response after 3 weeks of exposures while the cells from asthmatic donors showed an increase in TGF- $\beta$ release after 5 weeks of repeated exposures to DQ12. ${ }^{35} \mathrm{An}$ in vivo study revealed that mice and rats exposed to DQ12 developed chronic inflammation and intense lung fibrosis. ${ }^{38}$ Interestingly, we observed only proinflammatory increase in IL- 8 release at day 1 and in IL-6 at day 21 upon exposures to DQ12 in the presence of MDMs and at days 4 and 7 without MDMs.
The fluctuation of TNF- $\alpha$ and IL- $1 \beta$ release can be compared with in vivo data investigating gene expression upon exposure to carbon black nanoparticles. TNF- $\alpha$ receptor superfamily was up-regulated at days $1,3,14$, and 42 , while IL1 receptor was up-regulated at $3 \mathrm{~h}$ and days 1,2 , and $14 .^{72}$ As gene expression and protein release do not happen at the same time, we believe that correlation of our data with these results is very important. However, further studies are needed to confirm the correlation.

In summary, concentrations of overall release of TNF- $\alpha$, IL$1 \beta$, IL- 6 , and IL- 8 were in the same range for both (+) and (-) MDMs tissues (Supplementary Figures 13-16).

Profibrotic mediators are released after positive control, DQ12, Nanocyl, and Mitsui-7 Exposures in Laboratory 2 (KEs 1-4). Since chronic inflammation can trigger a profibrotic response, we used ELISA to investigate secretion of the profibrotic markers, TGF- $\beta$ (Figure 6a-f), fibronectin (Supplementary Figure 12), and COL1 (Figure $6 g-1)$. 
Several in vivo studies reported that Mitsui-7 exposures resulted in lung fibrosis ${ }^{12-14,73}$ as indicated by increased thickness of connective tissue in the alveolar region. In vitro investigation of $3 \mathrm{D}$ microtissues (combination of THP-1 macrophages, fibroblasts, and BEAS-2B epithelial cells) showed changed microtissue morphology and significant increase in gene expression of IL-1 $\beta$ and collagen types I and III, upon exposure to Mitsui- 7 after 4 and 7 days. ${ }^{74}$ This is in agreement with our observations after treatment with TGF$\beta$, as gradual thickening and contraction of tissues was observed at later time points (day 21); while Laboratory 2 observed only thickening of the tissues, Laboratories 1 and 3 observed also contraction of the tissue with nodule formation. Tissue contraction led to detachment and loss of cells from the membrane at day 14. An increase in $\alpha$-SMA and fibronectin was also observed after treatment with TGF- $\beta$ at all tested concentrations after 21 days. Similarly, the positive particle control DQ12 induced significant increase in fibronectin production at day 21 , and in COL1 production occurred at days 1, 14, and 21. EpiAlveolar tissues exposed to Nanocyl resulted in a statistically significant increase in fibronectin production at days 4 and 21 and in COL1 production at days 4,7 , and 21 . COL1 and fibronectin release was significantly increased at day 4 upon exposures to Mitsui-7 (at both lower $\left(\sim 1 \mu \mathrm{g} / \mathrm{cm}^{2}\right)$ and higher $\left(\sim 2 \mu \mathrm{g} / \mathrm{cm}^{2}\right)$ concentrations $)$. Furthermore, COL1 production was increased at days 7 and 14 (at both lower $\left(\sim 1 \mu \mathrm{g} / \mathrm{cm}^{2}\right)$ and higher $\left(\sim 2 \mu \mathrm{g} / \mathrm{cm}^{2}\right)$ concentrations), and at day 11 at lower $\left(\sim 1 \mu \mathrm{g} / \mathrm{cm}^{2}\right)$ concentration. Fibronectin release was significantly increased at days 14 and 18 (at the higher concentration) and days 18 and 21 (at the lower concentration).

All ELISA results (TNF- $\alpha$, IL- $\beta$, IL-6, IL- 8, TGF- $\beta$, fibronectin, and COL1) presented in absolute values (including all investigated positive controls) can be seen in Supplementary Figures 13-19. Statistical analysis of these data is presented in Supplementary Tables 1-7.

Epithelial Barrier Integrity Decreased upon Exposure to TGF- $\beta$ but Was Stable upon DQ12 and MWCNT Exposures (Laboratory 2). TEER was measured to assess barrier integrity of the EpiAlveolar tissues following exposures to test materials and controls. The TEER values remain high up to day 21 in untreated EpiAlveolar tissues $(+)$ and $(-)$ MDMs (Supplementary Figure 20). For the different material treatments, TEER was only measured after day 21 to avoid the potential removal of particles from the surface (Supplementary Figure 19). Although a drop in TEER values upon exposure to TGF- $\beta$ can be observed, no statistically significant decrease $(p$ $>0.05)$ in TEER values was observed for both $(-)$ and $(+)$ MDMs tissues, likely because of the high standard deviation of untreated tissues. Future studies are needed to identify the sources of variability in measuring TEER as it is one of the important assays to assess barrier integrity.

To confirm TEER results, LSM $x z$ projections were used to assess the cellular layer integrity of EpiAlveolar tissues $(+)$ and (-) MDMs after 21 days of treatments with different materials. During fibrosis, fibroblasts undergo excessive proliferation and there is increased ECM deposition. ${ }^{75}$ The (-) MDMs tissues show only a negligible increase in cellular layer thickness after DQ12 (daily deposition $\sim 0.2 \mu \mathrm{g} / \mathrm{cm}^{2}$ ) and Mitsui-7 (daily deposition $\sim 2 \mu \mathrm{g} / \mathrm{cm}^{2}$ ) treatment compared to BSA-treated cells. Interestingly, the $(+)$ MDMs tissues showed an increase in the cellular layer thickness upon exposures to DQ12 (daily deposition $\sim 0.2 \mu \mathrm{g} / \mathrm{cm}^{2}$ ) and Mitsui-7 (daily deposition $\sim 2$ $\mu \mathrm{g} / \mathrm{cm}^{2}$ ) compared to BSA-treated cells (Supplementary Figure 21).

\section{CONCLUSION}

This study characterizes a 3D in vitro alveolar tissue model comprised entirely of primary human cells to investigate its ability to predict pulmonary fibrosis. We demonstrated that the EpiAlveolar model recapitulates relevant lung phenotypes and functions and is stable at the ALI for at least 3 weeks. Future studies with EpiAlveolar could assess additional substances and the effectiveness of antifibrotic agents and the impact of human originated serum albumin to determine species-specific effects.

As with all studies, cause and effect analysis should be considered for all the protocols used to identify potential sources of variability (e.g., procedural variations or differences between chemicals and assays based on their manufacturer). ${ }^{73}$ Additionally, transitioning the EpiAlveolar model to chemically defined medium could increase the experimental reproducibility. This careful consideration will help maximize inter- and intralaboratory reproducibility and will be especially important as this model is considered for incorporation into international standards that may be used for regulatory testing.

\section{METHODS}

The handling and ability of the EpiAlveolar model to develop fibrosis end points upon exposure to the positive control (TGF- $\beta$ ) was confirmed in three laboratories. Afterward the particle studies were only done in Laboratory 2, which had access to the VITROCELL Cloud aerosolization system.

Characterization and Assessment of EpiAlveolar System Conducted at MatTek Corporation (Laboratory 1). Human Primary Cells Coculture Model MatTek EpiAlveolar. EpiAlveolar (MatTek Corporation, Massachusetts, USA) is a new, commercially available, organotypic model of the human alveolar tissue that is grown at the ALI. To produce the tissues, human endothelial cells are seeded onto the basal side of a microporous PET membrane insert (pore size $0.4 \mu \mathrm{m}$, Corning Costar 3460). Then, primary human fibroblasts and alveolar epithelial cells are seeded on the apical side of the insert membrane. EpiAlveolar tissues are produced from primary cells of lung origin from a disease-free, nonsmoking, 50 year old, male Caucasian donor. Once the tissues were fully differentiated, they were either shipped to Laboratory 2 for aerosol exposures or used at Laboratory 1 for characterization and optimization of the TGF- $\beta$ control treatment. The tissues were fed every other day (Monday, Wednesday, and Friday) with $5 \mathrm{~mL}$ of media (MatTek Corp, part no. ALV-100-M250) in the basal compartment and $75 \mu \mathrm{L}$ of media on the apical surface, following the manufacturer's protocol. When beginning the experiments, tissues were switched from fully supplemented media to media without the proprietary supplement "X", which the manufacturer has found to ablate the profibrotic effects induced by TGF- $\beta$.

Transepithelial Electrical Resistance (TEER). TEER was assessed at MatTek Corporation using an EVOM2 voltohmmeter and the EndOhm-12 culture cup chamber (World Precision Instruments, Florida, USA). Tissues were rinsed once with phosphate buffer saline (PBS) containing calcium and magnesium (MatTek Corp., part no. TEER-BUFFER) and transferred to the EndOhm-12 chamber containing PBS $(2 \mathrm{~mL}$ of PBS in the basal compartment and 0.5 $\mathrm{mL}$ in the apical compartment), and the raw resistance reading was recorded after it had stabilized. Using Microsoft Excel, a background reading of PBS alone was subtracted from the raw resistance values, and the background subtracted value was multiplied by the surface area $\left(1.12 \mathrm{~cm}^{2}\right)$. Two to four separate tissues were measured for each condition at each time point, and the mean and standard deviation across independent experiments was calculated. A TEER value greater than or equal to $300 \Omega \cdot \mathrm{cm}^{2}$ was considered to indicate an intact barrier. 
Hematoxylin and Eosin and Immunofluorescene Staining of EpiAlveolar Tissues. Tissues taken for histology and immunofluorescence were fixed overnight at room temperature in $10 \%$ buffered formalin (Sigma-Aldrich, Switzerland). Tissues were then rinsed with PBS, processed following standard practices, embedded in paraffin wax, sectioned, and adhered to slides. ${ }^{76-79}$ Sections of each tissue were stained by H\&E to assess tissue morphology. An Olympus VS120 Virtual Slide microscope (Olympus, Japan) was used to acquire images of the stained slides.

Immunofluorescent staining was conducted for $\alpha$-SMA, fibronectin, CK8, CK19, and VIM. Slides were placed in $0.05 \%$ citraconic anhydride in water, $\mathrm{pH}$ 7.4, and warmed for $45 \mathrm{~min}$ for antigen retrieval. After cooling, the slides were rinsed with tris-buffered saline (TBS) and blocked with $10 \%$ goat serum/1\% BSA/TBS for $1 \mathrm{~h}$ at room temperature. Primary antibodies (Abcam, MA, USA, and Millipore, MA, USA) diluted in $1 \%$ BSA/0.1\% Tween-20/TBS were applied to the slides for $1 \mathrm{~h}$ in a humidified chamber at room temperature. After this time, slides were washed, and the appropriate secondary antibodies were applied (Invitrogen, California, USA) for 1 h. Nuclei were stained with DAPI (4',6-diamidin-2-phenylindol), and after additional wash steps, coverslips were mounted with immunomount (Thermo Fisher Scientific Inc., MA, USA). All stained slides were imaged using an Olympus IX81 confocal microscope with Fluoview FV1000 (Olympus, Japan).

To determine the formation of tight junctions, EpiAlveolar tissues were fixed in formalin for $10 \mathrm{~min}$, then blocked with $10 \%$ goat serum and $0.1 \%$ Triton $\mathrm{X}-100$ for $1 \mathrm{~h}$. Tissues were then incubated with rabbit anti-ZO-1 (Zonula Occludens-1, Invitrogen no. 61-7300, Carlsbad, CA, USA), diluted $1: 100$ in PBS $+1 \%$ BSA and $0.1 \%$ Tween-20, for $2 \mathrm{~h}$ at RT. Tissues were rinsed in $10 \%$ goat serum + Triton-X-100 and incubated in goat anti-rabbit Alexa Fluor 555 (Invitrogen) diluted 1:400 for $1 \mathrm{~h}$ at RT, followed by washing in PBS and counterstaining with DAPI for $10 \mathrm{~min}$. ZO-1 was imaged using an Olympus IX81 microscope equipped with a FV1000 confocal system and FV10-ASW software package.

Transmission Electron Microscopy (TEM) of EpiAlveolar (Performed in Laboratory 2). In order to visualize lamellar bodies present in EpiAlveolar tissues, the tissues were fixed in $2.5 \%$ glutaraldehyde (Agar Scientific, Stansted, Essex, UK) in $0.15 \mathrm{M}$ HEPES (Fluka, Buchs, Switzerland) with an osmolarity of $670 \mathrm{mOsm}$ and adjusted to a $\mathrm{pH}$ of 7.35 . The cells remained in the fixative at 4 ${ }^{\circ} \mathrm{C}$ for at least $24 \mathrm{~h}$ before being further processed.

The tissues were then washed with 0.15 M HEPES three times for $5 \mathrm{~min}$, postfixed with $1 \%$ OsO4 (EMS, Hatfield, USA) in $0.1 \mathrm{M}$ sodium cacodylate buffer (Merck, Darmstadt, Germany) at $4{ }^{\circ} \mathrm{C}$ for 1 h. Thereafter cells were washed in $0.05 \mathrm{M}$ maleic acid/ $\mathrm{NaOH}$ buffer three times for $5 \mathrm{~min}$ and dehydrated in $70 \%, 80 \%$, and $96 \%$ ethanol (Alcosuisse, Switzerland) for $15 \mathrm{~min}$ each at room temperature. Subsequently, cells were immersed in $100 \%$ ethanol (Merck, Darmstadt, Germany) three times for $10 \mathrm{~min}$, and then they were submerged in ethanol-Epon (1:1) overnight at room temperature. The next day, cells were embedded in Epon (Fluka, Buchs, Switzerland) and left to harden at $60{ }^{\circ} \mathrm{C}$ for 5 days. Ultrathin sections $(70-80 \mathrm{~nm})$ were produced with an ultramicrotome UC6 (Leica Microsystems, Vienna, Austria), mounted on single slot copper grids, and stained with uranyless and lead citrate with an ultrostainer (Leica Microsystems, Vienna, Austria). TEM grids with mounted sections were used without any further treatment. Representative images were captured using a TEM (Fei Technai Spirit, Oregon, USA) operating at $120 \mathrm{kV}$ and equipped with a Veleta CCD camera (Olympus, Japan). Images were recorded at a resolution of $2048 \times$ 2048 pixels.

Surface Tension of the EpiAlveolar Tissues at the ALI. The surface tension was calculated based on a previously described protocol. ${ }^{54}$ Briefly, EpiAlveolar tissues were rinsed with PBS containing Ca and $\mathrm{Mg}$ and then left at the ALI without apical media for $48 \mathrm{~h}$ before measurement. Small droplets of dimethylphthalate/normal octanol (Fluka) $4: 1, \mathrm{v} / \mathrm{v}$ ratio, stained with $4 \mathrm{mg} / \mathrm{mL}$ of crystal violet (Sigma) to facilitate visualization of the test droplets were dropped on the apical side of EpiAlveolar tissues with a syringe. The method is based on the fact that the diameter of the deposited droplet decreases with decreasing surface tension and vice versa. Therefore, surface tension of the hypophase was estimated by the ratio of the area $(d)$ of the deposited droplet on the apical surface of cells (either A549 cells as a control $^{52}$ or EpiAlveolar tissues) and the area $\left(d_{0}\right)$ of the droplet measured prior to deposition (i.e., still attached to the micropipette, Supplementary Figure 2c, referred as a hanging droplet). To measure the droplet areas, photographs of the droplets were taken with a digital camera. The surface tension was subsequently calculated using a calibration curve (previously published for thin liquid substrates ${ }^{53}$ ) to evaluate the relationship between the $d / d_{0}$ ratio and the surface tension of the cell surface.

Profibrotic Response to TGF- $\beta$. TGF- $\beta$ was prepared according to the manufacturer's protocol (PeproTech, Inc., NJ, USA) at a stock concentration of $10 \mu \mathrm{g} / \mathrm{mL}$ in citric acid/BSA/PBS and stored at -20 ${ }^{\circ} \mathrm{C}$. A new aliquot of TGF- $\beta$ stock was thawed and added to the EpiAlveolar media fresh before each treatment.

Basolateral media samples were collected from the same individual tissues before every media change. The samples were analyzed for COL1, fibronectin, and TNF- $\alpha$ concentration using a Luminex kit according to the manufacturer's instructions (R\&D Systems, Minnesota, USA). All kit reagents were prepared as outlined in the manufacturer's protocol. Conditioned media samples were diluted at 1:50 for COL1 and fibronectin analysis and were left undiluted for TNF- $\alpha$ analysis to fall within the range of the standard curve. The media samples were mixed with the microparticle cocktail in duplicate wells of 96-well plates and incubated for $2 \mathrm{~h}$ on an orbital shaker. The samples were then washed on a magnetic plate washer to remove any unbound microparticles. The bound particles were resuspended in the kit's biotin-antibody cocktail and incubated for $1 \mathrm{~h}$ on an orbital shaker. Bound particles were washed, resuspended in Streptavidin-PE, and incubated for $30 \mathrm{~min}$ on an orbital shaker. The bound particles were given a final wash and resuspended in wash buffer to measure on the Bio-Plex Multiplex system (Bio-Rad, California, USA). Data was exported to Microsoft Excel before conducting statistical analyses.

Statistical Analysis. Statistical analyses were conducted using GraphPad Prism 8 software. The mean and standard deviation were calculated across replicate experiments. Statistically significant differences $(p \leq 0.05)$ were determined using a parametric one-way analysis of variance (ANOVA) with Tukey's HSD post hoc tests. Three independent experiments $(n=3)$ were performed.

Investigation of EpiAlveolar Response to Particle Exposures Conducted at the University of Fribourg (Laboratory 2). Material Preparation. BSA $\left(0.1 \%\right.$ in ultrapure $\left.\mathrm{H}_{2} \mathrm{O}\right)$ was sterile filtered $(0.2 \mu \mathrm{m}$ pore size, Nalgene, Thermo Fisher Scientific, Massachusetts, USA). BSA was used as the negative control for MWCNT-treated cells and as dispersant for the MWCNTs. The extremely hydrophobic properties of the CNTs, together with van der Waals forces and high particle surface area, lead to particle agglomeration in polar solvents. ${ }^{80}$ Therefore, dispersants (primarily proteins) are used to prevent agglomeration and stabilize the MWCNTs without substantial chemical surface modification. ${ }^{81-84}$ Both Mitsui-7 MWCNTs (Mitsui-7; Mitsui \& Co, Japan) and Nanocyl-7000 MWCNTs (Nanocyl; Nanocyl SA, Belgium; received from European Commission Joint Research Centre, Italy, sample JRCNM4000a), previously characterized within Nanogenotox project, ${ }^{85}$ were dispersed in $0.1 \%$ BSA. $^{41}$ Briefly, preweighed dry MWCNT powder was heat sterilized at $100{ }^{\circ} \mathrm{C}$ overnight and cooled, and a $50 \mu \mathrm{g} / \mathrm{mL}$ stock solution was prepared with $0.1 \%$ BSA. This suspension was sonicated using an ultrasonic bath sonicator (Elmasonic P30H, $100 \mathrm{~W}, 37 \mathrm{kHz}, 30 \%$ amplitude, Elma Schmidbauer $\mathrm{GmbH}$, Germany) for $3 \mathrm{~h}$ with continuous shaking and water cooling to disperse the MWCNTs and subsequently stored at $4{ }^{\circ} \mathrm{C}$ until use.

Silica Dörntruper quartz particles (DQ12; composed of $87 \%$ crystalline silica and amorphous silica with kaolinite impurities, particle size $\leq 5 \mu \mathrm{m}^{86}$ ), reported as a proinflammatory agent, ${ }^{87}$ were used as reference material.

Unlike MWCNTs, DQ12 particles are not hydrophobic; therefore they can be easily dispersed in ultrapure water. Therefore, DQ12 
particles were dispersed in ultrapure sterile filtered $\mathrm{H}_{2} \mathrm{O}$ at a concentration of $100 \mu \mathrm{g} / \mathrm{mL}$ following the same sonication procedure as for MWCNTs above.

All stock suspensions were sonicated for $1 \mathrm{~h}$ prior the exposure.

Material Characterization. Electron Microscopy. To investigate the deposition of all tested materials, TEM 300 mesh carbon coated copper grids were used. Prepared suspensions were pipetted onto the TEM grids. Additionally, TEM grids were placed into the exposure chamber prior to the exposure to visualize the aerosol deposited particles and to compare their appearance with suspended particles.

TEM grids with deposited material were used without any further treatment. Representative images were captured using a TEM (Fei Technai Spirit, Oregon, USA) operating at $120 \mathrm{kV}$ and equipped with a Veleta CCD camera (Olympus, Japan). Images were recorded at a resolution of $2048 \times 2048$ pixels.

Endotoxin Content. The endotoxin concentration in the MWCNTs and DQ12 suspensions was measured using the Pierce LAL Chromogenic Endotoxin Quantitation kit (Thermo Fisher Scientific, Massachusetts, USA), following the manufacturer's instructions, and all suspensions were below $0.5 \mathrm{EU} / \mathrm{mL}$. In order to avoid the artifacts resulting from interference of the material with an assay, three different concentrations of each particle suspension were tested, and the results were compared among each other.

Coculturing EpiAlveolar with Human Monocyte-Derived Macrophages (MDMs). Peripheral human blood monocytes were isolated from human blood buffy coats (Blood Donation Service, Bern University hospital, Switzerland), as previously described by Lehmann et al. $^{88}$ with subsequent $\mathrm{CD} 14^{+}$MicroBead separation (Miltenyi Biotec $\mathrm{GmbH}$, Germany) according to the manufacturer's protocol. Fresh monocytes were frozen for future use at a density of $6 \times 10^{6}$ cells $/ \mathrm{mL}$ in $90 \%$ fetal bovine serum (FBS, Gibco, Maryland, USA) and $10 \%$ dimethyl sulfoxide serving as cryopreservative. The cells were transferred to Nalgene Mr. Frosty Cryo $1{ }^{\circ} \mathrm{C}$ Freezing container $\left(-1{ }^{\circ} \mathrm{C} / \mathrm{min}\right.$ cooling rate, Thermo Fisher Scientific, Massachusetts, USA) and placed in a $-80{ }^{\circ} \mathrm{C}$ freezer, the vials were transferred to liquid nitrogen tank the following day. Monocytes were later thawed quickly in a $37{ }^{\circ} \mathrm{C}$ water bath and, before all the ice disappeared, diluted with 10 volumes of warmed FBS and subsequently centrifuged $(200 \mathrm{~g}, 5 \mathrm{~min})$. The FBS supernatant was aspirated, and cell pellet was resuspended in supplemented Roswell Park Memorial Institute 1640 (RPMI) medium (with 10\% FBS, 1\% penicillin/streptomycin (corresponds to 100 units $/ \mathrm{mL}$ penicillin and $100 \mu \mathrm{g} / \mathrm{mL}$ streptomycin), and $2 \mathrm{mM}$ L-glutamine (all Gibco, Maryland, USA)) and subsequently cultured for 6 days with the macrophage-colony stimulating factor (M-CSF, $[10 \mathrm{ng} / \mathrm{mL}]$ ) prior assembling the coculture at a density of $10^{6}$ cells $/ \mathrm{mL}$. The cocultures $(+)$ MDMs were assembled by gently pipetting MDMs in supplemented RPMI $(0.5 \mathrm{~mL} /$ insert) on top of the EpiAlveolar tissues (cultured in MatTek medium, $5 \mathrm{~mL}$ in the basal compartment) at a density of $5 \times 10^{4}$ $\mathrm{MDMs} / \mathrm{cm}^{2} 24 \mathrm{~h}$ prior to the first exposure. Tissues were transferred to ALI conditions by removing media from apical side of the insert and replacing the basal medium with $3 \mathrm{~mL}$ of MatTek cell culture medium prior to the first exposure.

As MDMs do not proliferate and the lifetime in culture is limited, fresh batches of MDMs from the same donor were reseeded every 7 days (on day 6 and day 13). Figure 3 shows the exposure scheme together with days of seeding MDMs. The medium from the upper compartment was removed the following morning (days 7 and 14) prior to further exposures. Three independent repetitions of the experiment were performed; therefore monocytes from three different donors were used, that is, one donor per repetition.

Air-Liquid Interface Exposures to MWCNTs and DQ12. Tissues were exposed at the ALI using the VITROCELL Cloud system. Briefly, the exposure system consists of a nebulizer, an exposure chamber, and a QCM (operated at $5 \mathrm{MHz}$ (Mega Hertz), detection limit $\left.0.1 \mu \mathrm{g} / \mathrm{cm}^{2}\right)$, allowing online measurements of the deposited dose. For each nebulization, $200 \mu \mathrm{L}$ of stock solution with $2 \mu \mathrm{L}$ of $0.09 \% \mathrm{NaCl}$ (NAAPREP physiological saline, GlaxoSmithKline, France) was added to the nebulizer (a vibrating mesh with a span of $2.5-6.0 \mu \mathrm{m}$ volumetric mean diameter (for DQ12 sample) or 10 $\mu \mathrm{m}$ volumetric mean diameter (for all the other samples)), Aeroneb Lab, Ireland). The vibrating perforated membrane at the neck of the nebulizer generates the aerosol into the exposure chamber. Inside the chamber, the aerosolized sample gently deposits onto the tissue surfaces maintained at the ALI. The flow rate is ideal for the aerosol to sufficiently mix to all sides of the chamber, hence resulting in uniform droplet deposition. One single exposure, that is, daily exposure to single particle dose, takes approximately $10-15 \mathrm{~min}$.

Cells were exposed apically at the ALI daily and kept at $37^{\circ} \mathrm{C}$ in $5 \% \mathrm{CO}_{2}$ throughout the whole exposure period. Tissues were exposed every working day (Monday-Friday) for 3 consecutive weeks. Media was collected every Monday, Wednesday, and Friday (days 2, 4, 7, 9, $11,14,16,18$, and 21); furthermore the medium was also collected at day 1.

Particle Interaction with EpiAlveolar. To investigate the interaction of Mitsui-7 within the EpiAlveolar tissues, the samples prepared for LSM analysis (see below) were also scanned using a $100 \times$ objective lens (numerical aperture 0.6 and 1.2) in Cytoviva dual mode fluorescence-enhanced dark-field microscopy setup (Cytoviva Inc., AL, USA). Because of strong scattering of the inserts, it was not possible to visualize Nanocyl and DQ12, mostly due to their small size. Therefore, the following experiment was performed.

Fixed tissues (cells on cell culture inserts, see below), stored in PBS, were scraped off the insert using a cell scraper, centrifuged (at $10000 \mathrm{~g}$ ) to remove excess PBS, resuspended in Kaiser's glycerol gelatin mounting medium (VWR, Switzerland) and dropped on a glass slide. As-prepared samples were visualized using a $100 \times$ objective lens (numerical aperture 0.6 and 1.2) in the Cytoviva dual mode fluorescence-enhanced dark-field microscopy setup (Cytoviva Inc., AL, USA) to investigate the interaction of the particles with the cells. Using this method, it is not possible to determine the cell type nor to distinguish between intracellular or cell membrane associated particles.

Cytotoxicity. $\mathrm{LDH}$ release into the tissue culture media as a result of cell membrane rupture is a well-known indicator of cytotoxicity. The amount of $\mathrm{LDH}$ release was evaluated using a commercially available LDH diagnostic kit (Roche Applied Science, Germany), according to the manufacturer's protocol. Each sample was measured in triplicate. $\mathrm{LDH}$ values are presented relative to the untreated cells. Cell cultures exposed apically to $0.2 \%$ Triton X-100 (100 $\mu \mathrm{L}$, submerged) for $24 \mathrm{~h}$ were used as a positive control for cell death. Basal medium only was collected, therefore no interference of the material with assay should occur. However, all materials were tested for potential interference with the assay; no interference was observed (data not shown).

Transepithelial Electrical Resistance (TEER). TEER measurement is used to assess the cell barrier integrity. Tissues grown on membrane inserts were washed with PBS with calcium and magnesium (TEERBUFFER, MatTek Corporation), and TEER was measured using chop-stick Millipore equipment (Millicell ERS-2, EMD Millipore Corporation, MA, USA). The TEER measurements were performed on two defined spots of each membrane inserts $(3 \mathrm{~mL}$ of TEERBUFFER in lower and $1 \mathrm{~mL}$ of TEER-BUFFER in upper compartment). Resistance values of two empty (without cells) membrane inserts ( $3 \mathrm{~mL}$ of TEER-BUFFER in lower and $1 \mathrm{~mL}$ of TEER-BUFFER in upper compartment) were averaged (after two independent sets of measurements) and subtracted from all the values for cell layer samples. The absolute values were multiplied by growth area of membrane inserts $\left(1.12 \mathrm{~cm}^{2}\right)$ and shown in $\left[\Omega \cdot \mathrm{cm}^{2}\right]$.

Laser Scanning Microscopy (LSM). At the end of the experiment (day 21), the tissues were fixed for $15 \mathrm{~min}$ in $4 \%$ paraformaldehyde in PBS at room temperature, subsequently washed 3 times with PBS, and stored in PBS at $4{ }^{\circ} \mathrm{C}$.

Prior to immunofluorescent staining, samples were treated with 0.1 $\mathrm{M}$ glycine for $15 \mathrm{~min}$ and permeabilized with $0.2 \%$ Triton X-100 and $1 \%$ BSA in PBS for $15 \mathrm{~min}$, both at room temperature. Antibodies were diluted in $0.1 \%$ BSA in PBS and incubated for $2 \mathrm{~h}$ with primary antibodies and then $2 \mathrm{~h}$ with secondary antibodies. The F-actin cytoskeleton was stained with rhodamine phalloidin (Molecular Probes, Thermo Fisher Scientific Inc., Massachusetts, USA) at 0.264 
$\mu \mathrm{M}$, DAPI at $2 \mu \mathrm{g} / \mathrm{mL}$ in PBS stained nuclei, macrophages were labeled using purified anti-human CD206 (Clone 15-2, Biolegend, UK, 1:50 dilution) and goat anti-mouse AlexaFluor 488 (Abcam, UK; 1:100 dilution), and tight junctions were labeled using polyclonal rabbit ZO-1 antibody (Thermo Fischer Scientific, Massachusetts, USA) and goat anti-rabbit DY488 (Invitrogen, Thermo Fischer Scientific, Massachusetts, USA). Following antibody incubation, cell culture inserts were embedded in Kiser's glycerol gelatin mounting medium (VWR, Switzerland). Cell morphology was visualized via an inverted confocal LSM 710 (Axio Observer.Z1, Carl Zeiss, Germany). Image processing was conducted with IMARIS 3D restoration software (Bitplane AG, Switzerland) or ImageJ. ${ }^{89}$

Proinflammatory Response to Positive Controls, MWCNTs, and $D Q 12$. IL- $1 \beta$, TNF- $\alpha$, and IL-8 release was assessed via ELISA, using the commercially available DuoSet ELISA Development diagnostic kit (R\&D Systems, Switzerland), according to manufacturer's protocol. Cells treated both apically (100 $\mu \mathrm{L}$, submerged) and basolaterally with $100 \mathrm{ng} / \mathrm{mL}$ or $1 \mu \mathrm{g} / \mathrm{mL}$ LPS (from Escherichia coli, strain O55:B5) served as positive controls for all three above-mentioned cytokine analyses. Cells treated with $100 \mathrm{ng} / \mathrm{mL}$ or $1 \mu \mathrm{g} / \mathrm{mL}$ TNF- $\alpha$ (ImmunoTools, Germany) served as the positive control for IL-8 assay, and cells treated with $10 \mathrm{ng} / \mathrm{mL}$ or $50 \mathrm{ng} / \mathrm{mL}$ TGF- $\beta 1$ (ImmunoTools, Germany) served a positive control for IL-1 $\beta$ and TNF- $\alpha$ release analysis. All positive controls were applied (apically $100 \mu \mathrm{L}$, submerged, and basolaterally) every Monday, Wednesday, and Friday (i.e., days 0, 2, 4, 7, 9, 11, 14, 16, and 18) together with media changes for all 3 weeks. The medium from the cell culture plate was changed and collected for further analysis every Monday, Wednesday, and Friday (days 2, 4, 7, 9, 11, 14, 16, and 18), and also collected at day 1 and day 21 . The collected medium $(3 \mathrm{~mL} /$ tissue $)$ was pooled from 2 samples for ELISA analysis, except for TNF- $\alpha$ and LPS treated samples, which were not pooled (only one tissue per condition was analyzed).

Profibrotic Response to Positive Control, MWCNT, and DQ12 Exposures. TGF- $\beta$, fibronectin, and COL1 release into the basolateral media was quantified using the respective ELISA DuoSet Development diagnostic kit, following the manufacturer's protocol. Based on the supplier's protocol, the TGF- $\beta$ was $\mathrm{pH}$ activated immediately before assaying. Cell cultures exposed both apically and basolaterally to $10 \mathrm{ng} / \mathrm{mL}$ or $50 \mathrm{ng} / \mathrm{mL}$ TGF- $\beta$ served as a positive control for fibronectin and COL1 release analysis, cells treated with $100 \mathrm{ng} / \mathrm{mL}$ or $1 \mu \mathrm{g} / \mathrm{mL}$ TNF- $\alpha$ served as the positive control for TGF- $\beta$ and fibronectin assay, and cells treated with $100 \mathrm{ng} / \mathrm{mL}$ or $1 \mu \mathrm{g} / \mathrm{mL}$ LPS served as positive control for COL1 and TGF- $\beta$ release analysis. All positive controls were applied (apically $100 \mu \mathrm{L}$, submerged, and basolaterally) every Monday, Wednesday, and Friday (i.e., days 0, 2, 4, $7,9,11,14,16$, and 18), together with media changes for all 3 weeks. The medium from cell culture plate was changed and collected for further analysis every Monday, Wednesday, and Friday (days 2, 4, 7, $9,11,14,16$, and 18), and also collected at day 1 and day 21 . The collected medium ( $3 \mathrm{~mL} /$ tissue) was pooled from 2 samples for ELISA analysis, except for TNF- $\alpha$ and LPS treated samples, which were not pooled (only one tissue per condition was analyzed).

Statistical Analysis. The proinflammatory cytokine release upon exposures to TGF- $\beta$, TNF- $\alpha$, and LPS is presented as relative to untreated cells. The cytokine release upon exposure to DQ12 is presented as relative to untreated cells (DQ12 are dispersed in ultrapure water), while MWCNT exposure results are presented as relative to BSA-treated cells, as BSA was used as MWCNT dispersant. For each data point, three independent experiments were performed, and all data are presented as the mean \pm standard deviation. Statistical analysis was performed using GraphPad Prism 6 software (GraphPad Software Inc., California, USA). A parametric one-way ANOVA with subsequent Dunnett test was performed for TEER and LDH data (Supplementary Figures 8 and 20). A parametric one-way analysis of variance (ANOVA) with subsequent Dunnett's test was performed for each data point (repetition) separately and if at least two data points out of three per treatment were statistically significant $(p<0.05)$, then the treatment was considered as statistically significant (Figures 5 and 6 and Supplementary Figures 10-12; statistical results presented in
Supplementary Tables 1-7). A scheme depicting the statistical analysis is presented in Supplementary Figure 22. Results were considered significant if $p<0.05$.

\section{ASSOCIATED CONTENT}

\section{Supporting Information}

The Supporting Information is available free of charge at https://pubs.acs.org/doi/10.1021/acsnano.9b06860.

Schematic depicting the adverse outcome pathway (AOP) for pulmonary fibrosis, EpiAlveolar characterization including micrograph showing a lamellar body and surface tension of EpiAlveolar, EpiAlveolar response upon exposure to TGF- $\beta$ confirmed in Laboratory 3, representative TEM images of suspended particles prior to nebulization, particle deposition during the experiment, representative LSM images showing presence of MDMs, Representative fluorescence-enhanced dark-field images of interaction of Mitsui-7 with EpiAlveolar, cytotoxicity data, representative LSM images presenting cellular morphology of EpiAlveolar exposed to BSA, Mitsui-7 MWCNTs, or TGF- $\beta$, IL-6, IL-8, and fibronectin release relative to negative control, release of all investigated cytokines in absolute values, TEER values upon material exposure, LSM images showing layer thickness upon material exposure, flowchart depicting statistical analysis, and tables summarizing results of statistical analysis for each cytokine separately (PDF)

\section{AUTHOR INFORMATION}

\section{Corresponding Author}

Barbara Rothen-Rutishauser - Adolphe Merkle Institute, University of Fribourg, 1700 Fribourg, Switzerland; () orcid.org/0000-0002-7805-9366; Phone: +41 2630095 02; Email: barbara.rothen@unifr.ch

\section{Authors}

Hana Barosova - Adolphe Merkle Institute, University of Fribourg, 1700 Fribourg, Switzerland; 이이.org/00000002-6728-4111

Anna G. Maione - MatTek Corporation, Ashland, Massachusetts 01721, United States

Dedy Septiadi - Adolphe Merkle Institute, University of Fribourg, 1700 Fribourg, Switzerland; (1) orcid.org/00000003-2353-7508

Monita Sharma - PETA International Science Consortium Ltd., London N1 9RL, U.K.

Laetitia Haeni - Adolphe Merkle Institute, University of Fribourg, 1700 Fribourg, Switzerland

Sandor Balog - Adolphe Merkle Institute, University of Fribourg, 1700 Fribourg, Switzerland; 이이.org/00000002-4847-9845

Olivia O'Connell - MatTek Corporation, Ashland, Massachusetts 01721, United States

George R. Jackson - MatTek Corporation, Ashland, Massachusetts 01721, United States

David Brown - Nano-Safety Research Group, Heriot-Watt University, Edinburgh EH14 4AS, U.K.

Amy J. Clippinger - PETA International Science Consortium Ltd., London N1 9RL, U.K.

Patrick Hayden - MatTek Corporation, Ashland, Massachusetts 01721, United States; BioSurfaces, Inc., Ashland, Massachusetts 01721, United States 
Alke Petri-Fink - Adolphe Merkle Institute and Department of Chemistry, University of Fribourg, 1700 Fribourg, Switzerland; (1) orcid.org/0000-0003-3952-7849

Vicki Stone - Nano-Safety Research Group, Heriot-Watt University, Edinburgh EH14 4AS, U.K.

Complete contact information is available at:

https://pubs.acs.org/10.1021/acsnano.9b06860

\section{Author Contributions}

H.B. performed all experiments in Laboratory 2, analyzed the data, and drafted the manuscript, A.G.M. performed all experiments in Laboratory 1 and analyzed the data, D.S. performed dark-field imaging and analyzed the data, M.S. analyzed the data, L.H. performed ELISA analysis in Laboratory 2, S.B. contributed to data analysis, O.O.C. and G.R.J. performed experiments in Laboratory 1 and analyzed the data, M.S., A.J.C., P.H., A.P.F., V.S., and B.R.R. designed and supervised the study. All authors contributed to the manuscript writing.

\section{Notes}

Ethics approval and consent to participate: The work involving primary monocytes isolated from human blood was approved by the committee of the Federal Office for Public Health Switzerland (reference number 611-1; Meldung A110635/2) for the Adolphe Merkle Institute.

The authors declare no competing financial interest.

\section{ACKNOWLEDGMENTS}

This work was supported by the PETA International Science Consortium Ltd. and the Adolphe Merkle Foundation. In addition, this project has received further funding from the European Union's Horizon 2020 research and innovation programme, PATROLS - Physiologically Anchored Tools for Realistic nanOmateriaL hazard aSsessment, under Grant Agreement No 760813. We kindly thank M. Spuch-Calvar for providing schemes for exposure scenario and AOP (Figure 3a, Supplementary Figure 1, and the TOC and abstract graphic), MJD. Clift for his valuable discussion during the study planning phase, and D. Allen, J. Hotchkiss, and E. Petersen for their valuable input during the manuscript drafting.

\section{REFERENCES}

(1) Hayashi, T.; Endo, M. Carbon Nanotubes as Structural Material and Their Application in Composites. Composites, Part B 2011, 42, 2151-2157.

(2) Britto, P. J.; Santhanam, K. S. V.; Rubio, A.; Alonso, J. A.; Ajayan, P. M. Improved Charge Transfer at Carbon Nanotube Electrodes. Adv. Mater. 1999, 11, 154-157.

(3) Avouris, P. Carbon Nanotube Electronics. Chem. Phys. 2002, 281, 429-445.

(4) Thostenson, E. T.; Ren, Z.; Chou, T.-W. Advances in the Science and Technology of Carbon Nanotubes and Their Composites: A Review. Compos. Sci. Technol. 2001, 61, 1899-1912.

(5) Andrews, R.; Weisenberger, M. C. Carbon Nanotube Polymer Composites. Curr. Opin. Solid State Mater. Sci. 2004, 8, 31-37.

(6) Pacurari, M.; Castranova, V.; Vallyathan, V. Single- and MultiWall Carbon Nanotubes versus Asbestos: Are the Carbon Nanotubes a New Health Risk to Humans? J. Toxicol. Environ. Health, Part A 2010, 73, 378-395.

(7) Maynard, A. D.; Baron, P. A.; Foley, M.; Shvedova, A. A.; Kisin, E. R.; Castranova, V. Exposure to Carbon Nanotube Material: Aerosol Release during the Handling of Unrefined Single-Walled Carbon
Nanotube Material. J. Toxicol. Environ. Health, Part A 2004, 67, 87107.

(8) Donaldson, K.; Poland, C. A.; Murphy, F. A.; MacFarlane, M.; Chernova, T.; Schinwald, A. Pulmonary Toxicity of Carbon Nanotubes and Asbestos - Similarities and Differences. Adv. Drug Delivery Rev. 2013, 65, 2078-2086.

(9) Ma-Hock, L.; Treumann, S.; Strauss, V.; Brill, S.; Luizi, F.; Mertler, M.; Wiench, K.; Gamer, A. O.; van Ravenzwaay, B.; Landsiedel, R. Inhalation Toxicity of Multiwall Carbon Nanotubes in Rats Exposed for 3 Months. Toxicol. Sci. 2009, 112, 468-481.

(10) Umeda, Y.; Kasai, T.; Saito, M.; Kondo, H.; Toya, T.; Aiso, S.; Okuda, H.; Nishizawa, T.; Fukushima, S. Two-Week Toxicity of Multi-Walled Carbon Nanotubes by Whole-Body Inhalation Exposure in Rats. J. Toxicol. Pathol. 2013, 26, 131-140.

(11) Mercer, R. R.; Scabilloni, J. F.; Hubbs, A. F.; Wang, L.; Battelli, L. A.; McKinney, W.; Castranova, V.; Porter, D. W. Extrapulmonary Transport of MWCNT following Inhalation Exposure. Part. Fibre Toxicol. 2013, 10, 38.

(12) Mercer, R. R.; Scabilloni, J. F.; Hubbs, A. F.; Battelli, L. A.; McKinney, W.; Friend, S.; Wolfarth, M. G.; Andrew, M.; Castranova, V.; Porter, D. W. Distribution and Fibrotic Response following Inhalation Exposure to Multi-Walled Carbon Nanotubes. Part. Fibre Toxicol. 2013, 10, 33.

(13) Mercer, R. R.; Hubbs, A. F.; Scabilloni, J. F.; Wang, L.; Battelli, L. A.; Friend, S.; Castranova, V.; Porter, D. W. Pulmonary Fibrotic Response to Aspiration of Multi-Walled Carbon Nanotubes. Part. Fibre Toxicol. 2011, 8, 21.

(14) Porter, D. W.; Hubbs, A. F.; Mercer, R. R.; Wu, N.; Wolfarth, M. G.; Sriram, K.; Leonard, S.; Battelli, L.; Schwegler-Berry, D.; Friend, S.; Andrew, M.; Chen, B. T.; Tsuruoka, S.; Endo, M.; Castranova, V. Mouse Pulmonary Dose- and Time Course-Responses Induced by Exposure to Multi-Walled Carbon Nanotubes. Toxicology 2010, 269, 136-147.

(15) Sharma, M.; Nikota, J.; Halappanavar, S.; Castranova, V.; Rothen-Rutishauser, B.; Clippinger, A. J. Predicting Pulmonary Fibrosis in Humans after Exposure to Multi-Walled Carbon Nanotubes (MWCNTs). Arch. Toxicol. 2016, 90, 1605-1622.

(16) Wilson, M. S.; Wynn, T. A. Pulmonary Fibrosis: Pathogenesis, Etiology and Regulation. Mucosal Immunol. 2009, 2, 103-121.

(17) Heyder, J.; Gebhart, J.; Rudolf, G.; Schiller, C. F.; Stahlhofen, W. Deposition of Particles in the Human Respiratory-Tract in the Size Range 0.005-15-Mu-M. J. Aerosol Sci. 1986, 17, 811-825.

(18) Vietti, G.; Lison, D.; van den Brule, S. Mechanisms of Lung Fibrosis Induced by Carbon Nanotubes: Towards an Adverse Outcome Pathway (AOP). Part. Fibre Toxicol. 2015, 13, 11.

(19) Labib, S.; Williams, A.; Yauk, C. L.; Nikota, J. K.; Wallin, H.; Vogel, U.; Halappanavar, S. Nano-Risk Science: Application of Toxicogenomics in an Adverse Outcome Pathway Framework for Risk Assessment of Multi-Walled Carbon Nanotubes. Part. Fibre Toxicol. 2015, 13, 15.

(20) Nikota, J.; Banville, A.; Goodwin, L. R.; Wu, D.; Williams, A.; Yauk, C. L.; Wallin, H.; Vogel, U.; Halappanavar, S. Stat-6 Signaling Pathway and Not Interleukin-1 Mediates Multi-Walled Carbon Nanotube-Induced Lung Fibrosis in Mice: Insights from an Adverse Outcome Pathway Framework. Part. Fibre Toxicol. 2017, 14, 37.

(21) Yu, Y.; Clippinger, A.; Alwine, J. C. Viral Effects on Metabolism: Changes in Glucose and Glutamine Utilization during Human Cytomegalovirus Infection. Trends Microbiol. 2011, 19, 360367.

(22) Nichols, J. E.; Niles, J. A.; Vega, S. P.; Argueta, L. B.; Eastaway, A.; Cortiella, J. Modeling the Lung: Design and Development of Tissue Engineered Macro- and Micro-Physiologic Lung Models for Research Use. Exp. Biol. Med. 2014, 239, 1135-1169.

(23) Rothen-Rutishauser, B.; Blank, F.; Mühlfeld, C.; Gehr, P. In Vitro Models of the Human Epithelial Airway Barrier to Study the Toxic Potential of Particulate Matter. Expert Opin. Drug Metab. Toxicol. 2008, 4, 1075-1089.

(24) Clippinger, A. J.; Allen, D.; Behrsing, H.; BéruBé, K. A.; Bolger, M. B.; Casey, W.; DeLorme, M.; Gaça, M.; Gehen, S. C.; Glover, K. 
P.; Hayden, P.; Hinderliter, P.; Hotchkiss, J. A.; Iskandar, A.; Keyser, B.; Luettich, K.; Ma-Hock, L.; Maione, A. G.; Makena, P.; Melbourne, $\mathrm{J}$.; et al. Pathway-Based Predictive Approaches for Non-Animal Assessment of Acute Inhalation Toxicity. Toxicol. In Vitro 2018, 52, $131-145$.

(25) Krug, H. F. Nanosafety Research-Are We on the Right Track? Angew. Chem., Int. Ed. 2014, 53, 12304-12319.

(26) Thurnherr, T.; Brandenberger, C.; Fischer, K.; Diener, L.; Manser, P.; Maeder-Althaus, X.; Kaiser, J.-P.; Krug, H. F.; RothenRutishauser, B.; Wick, P. A Comparison of Acute and Long-Term Effects of Industrial Multiwalled Carbon Nanotubes on Human Lung and Immune Cells In Vitro. Toxicol. Lett. 2011, 200, 176-186.

(27) Wang, L.; Luanpitpong, S.; Castranova, V.; Tse, W.; Lu, Y.; Pongrakhananon, V.; Rojanasakul, Y. Carbon Nanotubes Induce Malignant Transformation and Tumorigenesis of Human Lung Epithelial Cells. Nano Lett. 2011, 11, 2796-2803.

(28) Clift, M. J. D.; Endes, C.; Vanhecke, D.; Wick, P.; Gehr, P.; Schins, R. P. F.; Petri-Fink, A.; Rothen-Rutishauser, B. A Comparative Study of Different In Vitro Lung Cell Culture Systems to Assess the Most Beneficial Tool for Screening the Potential Adverse Effects of Carbon Nanotubes. Toxicol. Sci. 2014, 137, 55-64.

(29) Lenz, A. G.; Karg, E.; Lentner, B.; Dittrich, V.; Brandenberger, C.; Rothen-Rutishauser, B.; Schulz, H.; Ferron, G. A.; Schmid, O. A Dose-Controlled System for Air-Liquid Interface Cell Exposure and Application to Zinc Oxide Nanoparticles. Part. Fibre Toxicol. 2009, 6, 32.

(30) Loret, T.; Peyret, E.; Dubreuil, M.; Aguerre-Chariol, O.; Bressot, C.; le Bihan, O.; Amodeo, T.; Trouiller, B.; Braun, A.; Egles, C.; Lacroix, G. Air-Liquid Interface Exposure to Aerosols of Poorly Soluble Nanomaterials Induces Different Biological Activation Levels Compared to Exposure to Suspensions. Part. Fibre Toxicol. 2016, 13, 58.

(31) Kim, J. S.; Peters, T. M.; O'Shaughnessy, P. T.; AdamcakovaDodd, A.; Thorne, P. S. Validation of an In Vitro Exposure System for Toxicity Assessment of Air-Delivered Nanomaterials. Toxicol. In Vitro 2013, 27, 164-173.

(32) Polk, W. W.; Sharma, M.; Sayes, C. M.; Hotchkiss, J. A.; Clippinger, A. J. Aerosol Generation and Characterization of MultiWalled Carbon Nanotubes Exposed to Cells Cultured at the AirLiquid Interface. Part. Fibre Toxicol. 2015, 13, 20.

(33) Lacroix, G.; Koch, W.; Ritter, D.; Gutleb, A. C.; Larsen, S. T.; Loret, T.; Zanetti, F.; Constant, S.; Chortarea, S.; Rothen-Rutishauser, B.; Hiemstra, P. S.; Frejafon, E.; Hubert, P.; Gribaldo, L.; Kearns, P.; Aublant, J.-M.; Diabaté, S.; Weiss, C.; de Groot, A.; Kooter, I. AirLiquid Interface In Vitro Models for Respiratory Toxicology Research: Consensus Workshop and Recommendations. Appl. In Vitro Toxicol. 2018, 4, 91-106.

(34) Fernandez, I. E.; Eickelberg, O. The Impact of TGF-beta on Lung Fibrosis: From Targeting to Biomarkers. Proc. Am. Thorac. Soc. 2012, 9, 111-116.

(35) Chortarea, S.; Barosova, H.; Clift, M. J. D.; Wick, P.; Petri-Fink, A.; Rothen-Rutishauser, B. Human Asthmatic Bronchial Cells Are More Susceptible to Subchronic Repeated Exposures of Aerosolized Carbon Nanotubes at Occupationally Relevant Doses Than Healthy Cells. ACS Nano 2017, 11, 7615-7625.

(36) Endes, C.; Schmid, O.; Kinnear, C.; Mueller, S.; CamareroEspinosa, S.; Vanhecke, D.; Foster, E. J.; Petri-Fink, A.; RothenRutishauser, B.; Weder, C.; Clift, M. J. D. An In Vitro Testing Strategy towards Mimicking the Inhalation of High Aspect Ratio Nanoparticles. Part. Fibre Toxicol. 2014, 11, 40.

(37) Beyeler, S.; Chortarea, S.; Rothen-Rutishauser, B.; Petri-Fink, A.; Wick, P.; Tschanz, S. A.; von Garnier, C.; Blank, F. Acute Effects of Multi-Walled Carbon Nanotubes on Primary Bronchial Epithelial Cells from COPD Patients. Nanotoxicology 2018, 12, 699-711.

(38) Barbarin, V.; Nihoul, A.; Misson, P.; Arras, M.; Delos, M.; Leclercq, I.; Lison, D.; Huaux, F. The Role of Pro- and AntiInflammatory Responses in Silica-Induced Lung Fibrosis. Respir. Res. 2005, 6, 112.
(39) Blake, T. L.; DiMatteo, M.; Antonini, J. M.; McCloud, C. M.; Reasor, M. J. Subchronic Pulmonary Inflammation and Fibrosis Induced by Silica in Rats Are Attenuated by Amiodarone. Exp. Lung Res. 1996, 22, 113-131.

(40) Carter, J. M.; Driscoll, K. E. The Role of Inflammation, Oxidative Stress, and Proliferation in Silica-Induced Lung Disease: A Species Comparison. J. Environ. Pathol., Toxicol. Oncol. 2001, 20, 3343.

(41) Chortarea, S.; Zerimariam, F.; Barosova, H.; Septiadi, D.; Clift, M.; Petri-Fink, A.; Rothen-Rutishauser, B. Profibrotic Activity of Multi-Walled Carbon Nanotubes upon Prolonged Exposures in Different Human Lung Cell Types. Appl. In Vitro Toxicol. 2019, 5, 47.

(42) Vietti, G.; Ibouraadaten, S.; Palmai-Pallag, M.; Yakoub, Y.; Bailly, C.; Fenoglio, I.; Marbaix, E.; Lison, D.; van den Brule, S. Towards Predicting the Lung Fibrogenic Activity of Nanomaterials: Experimental Validation of an In Vitro Fibroblast Proliferation Assay. Part. Fibre Toxicol. 2013, 10, 52.

(43) van Berlo, D.; Wilhelmi, V.; Boots, A. W.; Hullmann, M.; Kuhlbusch, T. A. J.; Bast, A.; Schins, R. P. F.; Albrecht, C. Apoptotic, Inflammatory, and Fibrogenic Effects of Two Different Types of Multi-Walled Carbon Nanotubes in Mouse Lung. Arch. Toxicol. 2014, 88, 1725-1737.

(44) Poulsen, S. S.; Saber, A. T.; Williams, A.; Andersen, O.; Købler, C.; Atluri, R.; Pozzebon, M. E.; Mucelli, S. P.; Simion, M.; Rickerby, D.; Mortensen, A.; Jackson, P.; Kyjovska, Z. O.; Mølhave, K.; Jacobsen, N. R.; Jensen, K. A.; Yauk, C. L.; Wallin, H.; Halappanavar, S.; Vogel, U. MWCNTs of Different Physicochemical Properties Cause Similar Inflammatory Responses, but Differences in Transcriptional and Histological Markers of Fibrosis in Mouse Lungs. Toxicol. Appl. Pharmacol. 2015, 284, 16-32.

(45) Snyder-Talkington, B. N.; Dymacek, J.; Porter, D. W.; Wolfarth, M. G.; Mercer, R. R.; Pacurari, M.; Denvir, J.; Castranova, V.; Qian, Y.; Guo, N. L. System-Based Identification of Toxicity Pathways Associated with Multi-Walled Carbon Nanotube-Induced Pathological Responses. Toxicol. Appl. Pharmacol. 2013, 272, 476-489.

(46) Snyder-Talkington, B. N.; Dong, C.; Porter, D. W.; Ducatman, B.; Wolfarth, M. G.; Andrew, M.; Battelli, L.; Raese, R.; Castranova, V.; Guo, N. L.; Qian, Y. Multiwalled Carbon Nanotube-Induced Pulmonary Inflammatory and Fibrotic Responses and Genomic Changes Following Aspiration Exposure in Mice: A 1-Year Postexposure Study. J. Toxicol. Environ. Health, Part A 2016, 79, $352-366$.

(47) Flecknell, P. Replacement, Reduction, Refinement. ALTEX Alternatives to animal experimentation 2002, 19, 73-78.

(48) Paur, H. R.; Cassee, F. R.; Teeguarden, J.; Fissan, H.; Diabate, S.; Aufderheide, M.; Kreyling, W. G.; Hanninen, O.; Kasper, G.; Riediker, M.; Rothen-Rutishauser, B.; Schmid, O. In-Vitro Cell Exposure Studies for the Assessment of Nanoparticle Toxicity in the Lung-A Dialog between Aerosol Science and Biology. J. Aerosol Sci. 2011, 42, 668-692.

(49) Wang, L.; Mercer, R. R.; Rojanasakul, Y.; Qiu, A.; Lu, Y.; Scabilloni, J. F.; Wu, N.; Castranova, V. Direct Fibrogenic Effects of Dispersed Single-Walled Carbon Nanotubes on Human Lung Fibroblasts. J. Toxicol. Environ. Health, Part A 2010, 73, 410-422.

(50) Wang, X.; Lee, J. H.; Li, R.; Liao, Y. P.; Kang, J.; Chang, C. H.; Guiney, L. M.; Mirshafiee, V.; Li, L.; Lu, J.; Xia, T.; Hersam, M. C.; Nel, A. E. Toxicological Profiling of Highly Purified Single-Walled Carbon Nanotubes with Different Lengths in the Rodent Lung and Escherichia Coli. Small 2018, 14, 1703915.

(51) Fuchs, S.; Hollins, A.; Laue, M.; Schaefer, U.; Roemer, K.; Gumbleton, M.; Lehr, C.-M. Differentiation of Human Alveolar Epithelial Cells in Primary Culture: Morphological Characterization and Synthesis of Caveolin-1 and Surfactant Protein-C. Cell Tissue Res. 2003, 311, 31-45.

(52) Blank, F.; Rothen-Rutishauser, B. M.; Schurch, S.; Gehr, P. An Optimized In Vitro Model of the Respiratory Tract Wall to Study Particle Cell Interactions. J. Aerosol Med. 2006, 19, 392.

(53) Ohlinger, K.; Kolesnik, T.; Meindl, C.; Galle, B.; AbsengerNovak, M.; Kolb-Lenz, D.; Frohlich, E. Air-Liquid Interface Culture 
Changes Surface Properties of A549 Cells. Toxicol. In Vitro 2019, 60, 369-82.

(54) Im Hof, V.; Gehr, P.; Gerber, V.; Lee, M. M.; Schürch, S. In Vivo Determination of Surface Tension in the Horse Trachea and In Vitro Model Studies. Respir. Physiol. 1997, 109, 81-93.

(55) Srinivasan, B.; Kolli, A. R.; Esch, M. B.; Abaci, H. E.; Shuler, M. L.; Hickman, J. J. TEER Measurement Techniques for In Vitro Barrier Model Systems. J. Lab. Autom. 2015, 20, 107-126.

(56) Yue, X.; Shan, B.; Lasky, J. A. TGF- $\beta$ : Titan of Lung Fibrogenesis. Curr. Enzyme Inhib. 2010, 6, 67.

(57) Xu, Q.; Norman, J. T.; Shrivastav, S.; Lucio-Cazana, J.; Kopp, J. B. In Vitro Models of TGF-Beta-Induced Fibrosis Suitable for HighThroughput Screening of Antifibrotic Agents. Am. J. Physiol.: Renal Physiol. 2007, 293, F631-640.

(58) Biernacka, A.; Dobaczewski, M.; Frangogiannis, N. G. TGFBeta Signaling in Fibrosis. Growth Factors 2011, 29, 196-202.

(59) Walton, K. L.; Johnson, K. E.; Harrison, C. A. Targeting TGFBeta Mediated SMAD Signaling for the Prevention of Fibrosis. Front. Pharmacol. 2017, 8, 461.

(60) Ochs, M.; Weibel, E. R. Scientific Basis of Lung Function in Health and Disease. In Fishman's Pulmonary Diseases and Disorders, Se; Grippi, M., Elias, J., Fishman, J., Kotloff, R., Pack, A., Senior, R., Siegel, M., Eds.; McGraw-Hill Education: USA, 2008, Part 2.

(61) Lenz, A. G.; Stoeger, T.; Cei, D.; Schmidmeir, M.; Semren, N.; Burgstaller, G.; Lentner, B.; Eickelberg, O.; Meiners, S.; Schmid, O. Efficient Bioactive Delivery of Aerosolized Drugs to Human Pulmonary Epithelial Cells Cultured in Air-Liquid Interface Conditions. Am. J. Respir. Cell Mol. Biol. 2014, 51, 526-535.

(62) Drasler, B.; Kucki, M.; Delhaes, F.; Buerki-Thurnherr, T.; Vanhecke, D.; Korejwo, D.; Chortarea, S.; Barosova, H.; Hirsch, C.; Petri-Fink, A.; Rothen-Rutishauser, B.; Wick, P. Single Exposure to Aerosolized Graphene Oxide and Graphene Nanoplatelets Did Not Initiate an Acute Biological Response in a 3D Human Lung Model. Carbon 2018, 137, 125-135.

(63) Durantie, E.; Vanhecke, D.; Rodriguez-Lorenzo, L.; Delhaes, F.; Balog, S.; Septiadi, D.; Bourquin, J.; Petri-Fink, A.; RothenRutishauser, B. Biodistribution of Single and Aggregated Gold Nanoparticles Exposed to the Human Lung Epithelial Tissue Barrier at the Air-Liquid Interface. Part. Fibre Toxicol. 2017, 14, 49.

(64) Gangwal, S.; Brown, J. S.; Wang, A.; Houck, K. A.; Dix, D. J.; Kavlock, R. J.; Hubal, E. A. C. Informing Selection of Nanomaterial Concentrations for ToxCast In Vitro Testing Based on Occupational Exposure Potential. Environ. Health Perspect. 2011, 119, 1539-1546.

(65) Huaux, F.; Louahed, J.; Hudspith, B.; Meredith, C.; Delos, M.; Renauld, J.-C.; Lison, D. Role of Interleukin-10 in the Lung Response to Silica in Mice. Am. J. Respir. Cell Mol. Biol. 1998, 18, 51-59.

(66) Chortarea, S.; Clift, M. J. D.; Vanhecke, D.; Endes, C.; Wick, P.; Petri-Fink, A.; Rothen-Rutishauser, B. Repeated Exposure to Carbon Nanotube-Based Aerosols Does Not Affect the Functional Properties of a 3D Human Epithelial Airway Model. Nanotoxicology 2015, 9, 983-993.

(67) Pinkerton, K. E.; Gehr, P.; Castañeda, A.; Crapo, J. D. Architecture and Cellular Composition of the Air-Blood Tissue Barrier. In Comparative Biology of the Normal Lung, 2nd ed.; Parent, R. A., Ed.; Academic Press: San Diego, 2015; Chapter 9, pp 105-117.

(68) Vanhee, D.; Gosset, P.; Marquette, C. H.; Wallaert, B.; Lafitte, J. J.; Gosselin, B.; Voisin, C.; Tonnel, A. B. Secretion and mRNA Expression of TNF Alpha and IL-6 in the Lungs of Pneumoconiosis Patients. Am. J. Respir. Crit. Care Med. 1995, 152, 298-306.

(69) Edelblum, K. L.; Turner, J. R. Epithelial Cells: Structure, Transport, and Barrier Function. In Mucosal Immunology, 4th ed.; Mestecky, J., Strober, W., Russell, M. W., Kelsall, B. L., Cheroutre, H., Lambrecht, B. N., Eds.; Academic Press: Boston, USA, 2015; Chapter 12, pp 187-210.

(70) Turner, M. D.; Nedjai, B.; Hurst, T.; Pennington, D. J. Cytokines and Chemokines: At the Crossroads of Cell Signalling and Inflammatory Disease. Biochim. Biophys. Acta, Mol. Cell Res. 2014, 1843, 2563-2582.
(71) Martinet, Y.; Menard, O.; Vaillant, P.; Vignaud, J.; Martinet, N. Cytokines in Human Lung Fibrosis. In Toxicology - From Cells to Man; Seiler, J. P., Kroftová, O., Eybl, V., Eds.; Springer: Berlin, 1996; pp 127-139.

(72) Husain, M.; Kyjovska, Z. O.; Bourdon-Lacombe, J.; Saber, A. T.; Jensen, K. A.; Jacobsen, N. R.; Williams, A.; Wallin, H.; Halappanavar, S.; Vogel, U.; Yauk, C. L. Carbon Black Nanoparticles Induce Biphasic Gene Expression Changes Associated with Inflammatory Responses in the Lungs of C57BL/6 Mice Following a Single Intratracheal Instillation. Toxicol. Appl. Pharmacol. 2015, 289, 573-588.

(73) Rahman, L.; Jacobsen, N. R.; Aziz, S. A.; Wu, D.; Williams, A.; Yauk, C. L.; White, P.; Wallin, H.; Vogel, U.; Halappanavar, S. MultiWalled Carbon Nanotube-Induced Genotoxic, Inflammatory and ProFibrotic Responses in Mice: Investigating the Mechanisms of Pulmonary Carcinogenesis. Mutat. Res., Genet. Toxicol. Environ. Mutagen. 2017, 823, 28-44.

(74) Kabadi, P. K.; Rodd, A. L.; Simmons, A. E.; Messier, N. J.; Hurt, R. H.; Kane, A. B. A Novel Human 3D Lung Microtissue Model for Nanoparticle-Induced Cell-Matrix Alterations. Part. Fibre Toxicol. 2019, 16, 15.

(75) Funke, M.; Geiser, T. Idiopathic Pulmonary Fibrosis: The Turning Point Is Now! Swiss Med. Wkly. 2015, 145, w14139.

(76) Winsor, L. Tissue processing. In Laboratory Histopathology; Winsor, L., Ed.; Churchill Livingstone: New York, 1994; pp 4.2.14.2.39.

(77) Hopwood, D. Fixation and Fixatives. In Theory and practice of histological techniques; Bancroft, J. D., Stevens, A., Eds.; Churchill Livingstone: New York, 1996; pp 63-84.

(78) Carson, F.; Coppellano, C. H. In Histotechnology, A SelfInstructional Text, 4th ed.; Carson, F., Coppellano, C. H., Eds.; American Society for Clinical Pathology: Chicago, 2002.

(79) Clayden, E. C. Practical Section Cutting and Staining, 5th ed.; Clayden, E. C., Ed.; Churchill Livingstone: Edinburgh, 1971.

(80) Ryabenko, A. G.; Dorofeeva, T. V.; Zvereva, G. I. UV-VISNIR Spectroscopy Study of Sensitivity of Single-Wall Carbon Nanotubes to Chemical Processing and van-der-Waals SWNT/ SWNT Interaction. Verification of the SWNT Content Measurements by Absorption Spectroscopy. Carbon 2004, 42, 1523-1535.

(81) Nepal, D.; Geckeler, K. E. Proteins and Carbon Nanotubes: Close Encounter in Water. Small 2007, 3, 1259-1265.

(82) Richard, C.; Balavoine, F.; Schultz, P.; Ebbesen, T. W.; Mioskowski, C. Supramolecular Self-Assembly of Lipid Derivatives on Carbon Nanotubes. Science 2003, 300, 775-778.

(83) Ge, C.; Du, J.; Zhao, L.; Wang, L.; Liu, Y.; Li, D.; Yang, Y.; Zhou, R.; Zhao, Y.; Chai, Z.; Chen, C. Binding of Blood Proteins to Carbon Nanotubes Reduces Cytotoxicity. Proc. Natl. Acad. Sci. U. S. A. 2011, 108, 16968-16973.

(84) Nagaraju, K.; Reddy, R.; Reddy, N. A Review on Protein Functionalized Carbon Nanotubes. J. Appl. Biomater. Funct. Mater. 2015, 13, 301-312.

(85) Nanogenotox. Facilitating the Safety Evaluation of Manufactured Nanomaterials By Characterising Their Potential Genotoxicity Hazard. Final report, 2013.

(86) Robock, K. Standard Quartz DQ12 $<5 \mu \mathrm{m}$ for Experimental Pneumoconiosis Research Projects in the Federal Republic of Germany. Ann. Occup. Hyg. 1973, 16, 63.

(87) Clouter, A.; Brown, D.; Höhr, D.; Borm, P.; Donaldson, K. Inflammatory Effects of Respirable Quartz Collected in Workplaces versus Standard DQ12 Quartz: Particle Surface Correlates. Toxicol. Sci. 2001, 63, 90.

(88) Lehmann, A.; Brandenberger, C.; Blank, F.; Gehr, P.; RothenRutishauser, B. A 3D Model of the Human Epithelial Airway Barrier. In Alternatives to animal testing; Maguire, T., Novik, E., Eds.; Artech House: London, 2010; pp 239-260.

(89) Schneider, C. A.; Rasband, W. S.; Eliceiri, K. W. NIH Image to ImageJ: 25 Years of Image Analysis. Nat. Methods 2012, 9, 671. 